\title{
Chemical Biology: What is Its Role in Drug Discovery?
}

\author{
Lisa Pirrie and Nicholas J. Westwood \\ School of Chemistry and Biomedical Sciences Research Complex, \\ University of St Andrews and EaStCHEM, St Andrews, Scotland,
}

UK

\section{Introduction}

For better or worse, there are considerable changes underway in the world of drug discovery. Whilst it is unclear what the future will bring, one possibility is a strategic shift in the modus operandi of the large pharmaceutical companies. One consequence of a shift away from high level investment in "in-house" research and development by pharma could be increased industrial interest in early stage research carried out in biotech, government or charity-funded research centres and academia. In many of these institutions, this type of research is often referred to as "chemical biology". But what is chemical biology? In this chapter we take a less-trodden path to addressing this question with the overall aim of shedding some light on areas of chemical biology which are relevant to drug discovery.

Chemical biology is a difficult topic to define in a few sentences since the subject is very wide ranging. Recent attempts have included an excellent review article in ChemBioChem written by some of the experts in the field (Altmann et al., 2009). A book focusing on the new frontiers in chemical biology has also recently been published (Bunnage, 2010). Interestingly, the Editorial in this book identifies "..reducing the high levels of attrition currently seen in "proof-of concept" Phase II clinical trials" as a key future challenge in drug discovery. It goes on to argue that this can only be achieved through "a much deeper knowledge of biological systems in order to identify and validate those biomolecular targets for which there is the highest possible confidence of disease-relevance in humans". The Editor concludes by proposing that chemical biology has great potential to help address the challenges that have been summarised above. So again we ask what is chemical biology?

Several excellent articles cover this issue in the New Frontiers book (Bunnage, 2010), but here we use an alternative method of probing what chemical biology really involves at the grass roots level. Our goal was to reflect on whether chemical biology, as currently practiced, really is and will be of interest to the drug discovery community in the future. Our chosen approach was to provide a review of all the chemical biology papers which were published in 2009 in the RSC journal Organic and Biomolecular Chemistry. Due to the number of papers, over 300, coverage of many of these exciting pieces of research is brief. We apologise for this and for any we may have inadvertently overlooked. However, our goal was to bring this body of work together in an organised and accessible form and to try and continue efforts to define what chemical biology involves. The chapter is split into three 
main sections focusing on: (1) advances in the core technologies in chemical biology; (2) progress in the established research areas and (3) emerging areas in chemical biology. The chapter concludes with a brief discussion of the sub-areas of chemical biology that have been identified and attempts to assess which, if any, are of relevance to the future of drug discovery.

\section{The core techniques in chemical biology}

The core skills of chemical biology, including synthetic chemistry, molecular biology, protein crystallography and many others, are often viewed as "standard" and we have therefore decided to cover the majority of the developments in these core techniques in section 3 in connection with their applications. However, progress in three areas is highlighted here:

\subsection{Analytical techniques in chemical biology}

Work continues on the development of novel reagents and methods to address the many analytical challenges presented by chemical biology. For example, the key issue of the detection of post-translational modification (PTM) in proteins has been studied by Stoyanovsky (Sengupta et al., 2009). This work involves the development of a novel method of assessing S-nitroso PTMs, that complements the established biotin switch assay (for a schematic representation see Figure 1A). The technique works by trapping the thiyl radical 2, which is generated when an $S$-nitroso group spits out $\mathrm{NO}$ on irradiation with visible light. This method uses 5,5-dimethyl-1-pyrroline- $N$-oxide as the trapping agent to give $\mathbf{3}$ and the amount of this adduct can be assessed via western blotting methods. Gene silencing requires the selective methylation of the 5-position of cytidines in DNA. This important PTM therefore provides control of gene function. A novel nonenzymatic method for detecting 5methylcytosine has been reported by reaction of the nucleobase with a photosensitive uridine derivative (Scheme 1B) (Ogino et al., 2009). It was demonstrated that the yield of the photoligation between 5-methylcytosine and photosensitive 5-vinyl-2'-deoxyuridine derivatives was 5-6 fold higher than with cytosine itself, allowing detection of this important PTM.

Progress continues to be made in the synthesis of molecular imprints that are capable of recognising specific proteins in complex mixtures, such as human serum. Micro-contact imprinting was used to prepare an imprint of creatine kinase (Yi-Wen Chen et al., 2009). The use of a fluorescent imprinted polymer for detecting chiral amines has also been reported (Nguyen\&Ansell, 2009). Three strategies for the recognition of paracetamol through molecular imprinting of materials have been described (Rosengren-Holmberg et al., 2009). Further exploring aspects of the recognition of biomolecules, a highly sensitive enzyme immunoassay has been developed by raising antibodies to an anthrose-containing trisaccharide derived from Bacillus anthracis (Dhenin et al., 2009). Careful characterisation of the epitope recognised by the antibody was reported. An ingenious method of detecting spores from the Bacillus phylum of bacteria has also been described (Lusvarghi et al., 2009). In this approach a biotinylated multivalent scaffold was used in conjunction with a sporebinding heptapeptide. A related report describes the ability of resin beads, functionalised with clustered or individual peptides, to bind cells providing a novel cell adhesion assay (Foillard et al., 2009). 
(A)

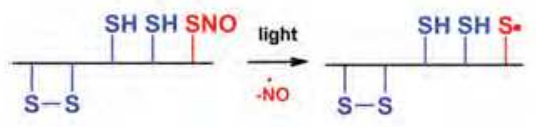

1
2

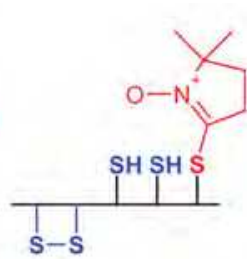

3

(B)

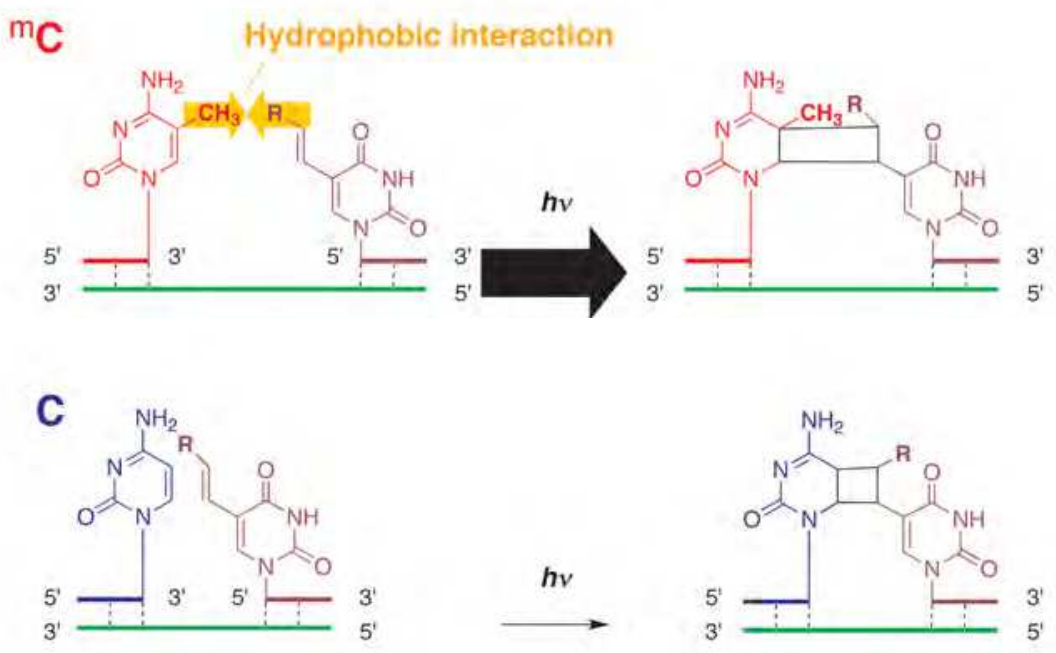

Fig. 1. (A) S-(de)nitrosation of thiol-containing protein $\mathbf{1}$ to give the thiyl radical 2 followed by spin-trapping of this radical by DMPO giving 3 . Chemiluminescence-monitored decomposition of the $\mathrm{SNO}$ group upon irradiation and western blotting analysis of the DMPO-tagged proteins (Sengupta et al., 2009). http://dx.doi.org/10.1039/b817981f (B) Strategy for the detection of 5-methylcytosine by photoligation with vinyluridine derivatives. This reaction is enhanced due to an increased hydrophobic interaction between the two reactants (Ogino et al., 2009) http://dx.doi.org/10.1039/b904941j. Reproduced by permission of The Royal Society of Chemistry.

The analysis of $\mathrm{pH}$ in biological systems is very important. As an aid to this, two novel $\mathrm{pH}$ sensors have been reported. One, based on 5(6)-carboxynaphthofluorescein, has been applied to the study of ion channels,(Butterfield et al., 2009) whilst a second study focused on the use of dextran nanoparticles as a means of supporting both a $\mathrm{pH}$ indicator dye (FITC) and a reference dye (Schulz et al., 2009). In other work, the analysis of the kinetics of bile acid transport by flow cytommetry has been advanced by the development of novel dansyllabelled cholic acid derivatives (Rohacova et al., 2009). The assessment of the purity of peptide hormones has also been improved by the use of a dynamic combinatorial chemistry approach to identify a metal-dye combination that delivered a sensor with the required discriminatory power (Zaubitzer et al., 2009). A new assay format for the analysis of the DNA-binding protein NF-kB has been developed (Altevogt et al., 2009). 


\subsection{Computational techniques}

The application of computational methods continues to advance and provide novel insights in chemical biology. Computational methods were used to deduce the mechanism and important residues in the glycoside hydrolysis reaction by endo- $\beta-1,4$-xylanase (Soliman et al., 2009; Soliman et al., 2009). By using quantum chemical calculations, a new mechanism for the inhibition of trichodiene synthase by an analogue of farnesyl diphosphate (FPP) containing a cyclopropane ring has been reported (Hong\&Tantillo, 2009). The phosphate transfer mechanism of uridine-cytidine kinase 2 has been investigated using computational methods (Smith et al., 2009). The interactions between tryptophan residues of membrane peptides and proteins and the lipid bilayer has been studied using both experimental, NMR titrations, and computational methods (Blaser et al., 2009). Applications of computational chemistry in inhibitor design remain important with, for example, the study of sulfonylhydrazines as potential metalloprotease inhibitors being reported (Rouffet et al., 2009). The results of these studies will be used to guide synthetic efforts towards potent inhibitors. Computational chemistry has also been used to design conjugates of docetaxel with increased solubility for use in a nano-emulsion formulation (Huynh et al., 2009). Other examples of the use of computational methods occur throughout this review.

\subsection{The development of imaging methods}

The ability to analyse and in some cases image important anions, cations or other chemical entities in live cells is becoming very important in chemical biology. This has triggered considerable activity in the design and synthesis of novel sensors. For example, several novel anion- and cation-sensors have been reported. In the context of anion-sensors, an indoleazadiene conjugate that is a useful fluoride ion sensor has been discovered (Shiraishi et al., 2009). In addition, fluoride ion recognition by urea (Perez-Ruiz et al., 2009) and thioureacontaining (Veale et al., 2009) sensors has been reported. In the thiourea example, a bidirectional PET-based system was shown to be responsive to $\mathrm{AcO}-$ and $\mathrm{H}_{2} \mathrm{PO}_{4}^{-}$anions as well as fluoride (Veale et al., 2009). The importance of allosteric effects has been assessed in a tetrapodal imidazolium-derived calix[4]arene receptor that recognises a range of anions (Willans et al., 2009). The use of porphyrin and $N$-confused porphyrin systems to detect anions has also been progressed (Toganoh et al., 2009). The sensing of inorganic phosphate by a bisdipicolylamine ligand has been assessed using calorimetric techniques (Drewry et al., 2009).

Chemosensors for $\mathrm{Cu}^{2+}$ in aqueous solution based on an unsymmetrical 4,5diaminonaphthalimide (Junhai Huang et al., 2009) or calix[4]arenes (Gruber et al., 2009) have been developed. The interesting observation by Jiang that suitably substituted $\mathrm{N}$ acylhydrazones are converted to highly fluorescent 1,3,4-oxadiazoles in the presence of $\mathrm{Cu}^{2+}$ provided a sensitive method of detecting $\mathrm{Cu}^{2+}$ levels (Figure 2A) (Ai-Fang Li et al., 2009). This chemistry has also been applied to the detection of methylmercury $\left(\mathrm{MeHg}^{+}\right)$cations in living cells and organisms (Young-Keun Yang et al., 2009). In two separate but related reports a dithiolane-linked thiorhodamine dimer (Weimin Liu et al., 2009) and a tridentate diaza-oxa-containing BODIPY derivative ( $\mathrm{Lu}$ et al., 2009) have been developed for the detection of $\mathrm{Hg}^{2+}$ ions in living cells. A phosphane disulfide derivative has also been shown to be a highly selective and sensitive $\mathrm{Hg}^{2+}$ sensor (Ha-Thi et al., 2009). A ruthenium-based metallocrown complex senses the presence of $\mathrm{Li}^{+}$ions in both water and in serum providing a fluorescent readout (Rochat et al., 2009). Sensors for other compounds including glucose (Sharrett et al., 2009), spermidine and spermine (Tanima et al., 2009), palmatine and 
dehydrocorydaline (Chunju Li et al., 2009), and acetylcholine (Dumartin et al., 2009) have also been described. A novel ditopic receptor based on resocinarene has been reported for the binding of acetylcholine and ammonium cations (Salorinne et al., 2009). An artificial receptor for carbohydrates has been designed and was shown to be selective for disaccharides over monosaccharides in organic solvent (Mazik\&Buthe, 2009). A europiumbased luminescence assay for the detection of lactate and citrate in biological fluids has been developed by Parker (Figure 2B) (Pal et al., 2009). The results obtained using this approach were compared to those obtained using a commonly used citrate lyase kit and the outcome found to be almost identical. The sensing of biological thiols has also been advanced (Wang et al., 2009). This report describes the synthesis of a merocyanine-based probe that is cleaved by thiols to give two compounds one of which is a chromophore, the other a fluorophore.

Many of the sensors described above rely on the use of established dyes. However, the chemical biology community continues to drive forward the optimisation of existing and the discovery of new fluorophores. The synthesis of a series of novel cyanine dyes, using a combination of solid phase and microwave irradiation, covering the whole colour range has been reported by Bradley (Figure 2C) (Lopalco et al., 2009). The synthesis and characterisation of napthalenediimide cyclophane dyes has also been explored (Gabutti et al., 2009). Novel tetrathiafulvalene-dicyanovinyl donor-acceptor chromophores, (Andersson et al., 2009) and new clickable fluorophores (Kele et al., 2009; Tsou et al., 2009) have also been developed. In one of these systems (Kele et al., 2009), the versatility of the new fluorophore was demonstrated in both cell labelling experiments and applications to the labelling of azide modified surface glycans. The synthesis of novel 7(dimethylamino)fluorene-based probes and characterisation of their binding to human serum albumin has been described by Park and Hamilton et al (Figure 2D) (Park et al., 2009). Competition studies with known human serum albumin binders enabled the binding sites of these probes to be established.

Established imaging techniques involve the use of either radiotracers or lanthanide-based complexes and progress in both of these areas continues at pace. A new synthetic approach to the positron-emitting radiotracer $\left[{ }^{18} \mathrm{~F}\right]$-2-fluoro-2-deoxy-D-glucose ([18F]-FDG) has been reported (L. J. Brown et al., 2009). The synthesis of [ $\left.{ }^{18} \mathrm{~F}\right]-$ and $\left[{ }^{13} \mathrm{C}\right]-$ labeled $\mathrm{N}$-benzyl-isatin sulphonamides have also been described. These reagents are of use in the study of apoptosis in living systems (D. Zhou et al., 2009). A novel ${ }^{111} \mathrm{In}(\mathrm{III})$-containing radio-pharmaceutical based on oxytocin has also been shown to have potential applications in the diagnosis of tumours over-expressing oxytocin receptors (Barge et al., 2009). Details of the mechanism of uptake of luminescent lanthanide probes by cells has concluded that the major uptake mechanism is macropinocytosis (New\&Parker, 2009). The coupling of Eu(III) complexes to gold nanoparticles (Bonnet et al., 2009), and trinucleotides (DNA only or chimeric RNA/DNA)(Escudier et al., 2009) has also been described. Novel coumarin-based europium complexes have been synthesised and their photophysical properties determined in water (Feau et al., 2009). The preparation of bifunctional chelating agents containing Gd(III) has been achieved using a 4-component Ugi coupling reaction (Tei et al., 2009).

In addition to the further development of existing technologies, a series of novel reports that fall into the imaging category have also appeared. For example, substituted phenothiazine dyes have been shown to aggregate into fluorescent organic nanoparticles (Lin et al., 2009). These particles surprisingly light up the lysosomes of cancer cells but not normal cells. The synthesis and use of novel quadrupolar Bodipy dyes in FLIM experiments in HeLa cells has 
also been reported (Didier et al., 2009). Imaging of a variant of the protein haloalkane dehalogenase (HD) in cells has also been achieved by the development of a novel fluorogenic affinity label derived from an HD substrate (Watkins et al., 2009). A key feature of the affinity label is that it requires unmasking by an intracellular esterase and the authors envisage applications in pulse-chase experiments and high-content screening amongst other protocols. Fluorescent cholinesterase inhibitors have been used to identify the formation of $\beta$-amyloid plaques in brain samples from animals and humans affected with Alzheimer's disease (Elsinghorst et al., 2009).

(A)

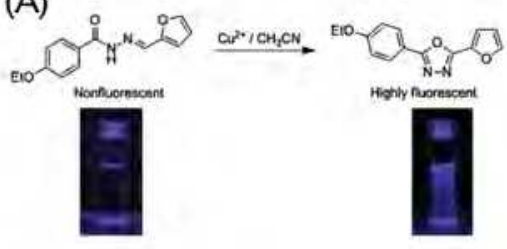

(C)

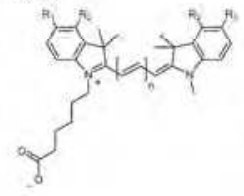

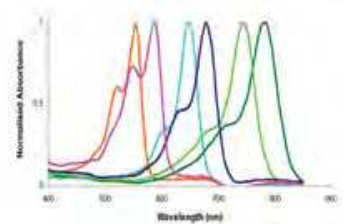

(D)

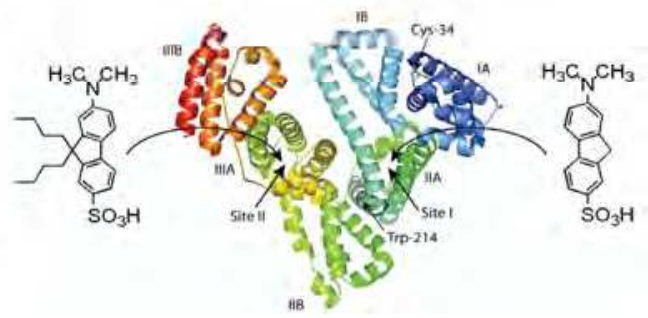

Fig. 2. (A) Conversion of $N$-acylhydrazones which are non-fluorescent to highly fluorescent 1,3,4-oxadiazoles on treatment with $\mathrm{Cu}^{2+}$.(A. F. Li et al., 2009)

http://dx.doi.org/10.1039/b811612a (B) Europium(III) complex and a comparison of the results obtained using this new assay to those obtained with a commercially available citrate lyase kit.(Pal et al., 2009) http:/ / dx.doi.org/10.1039/b901251f (C) General structure of the novel cyanine dyes and their corresponding absorption spectra.(Lopalco et al., 2009) http:/ / dx.doi.org/10.1039/b820719b (D) 7-(dimethylamino)fluorene-based probes and their binding sites in human serum albumin.(Park et al., 2009)

http:/ / dx.doi.org/10.1039/b911605b Reproduced by permission of The Royal Society of Chemistry.

\section{Progress in established research areas}

\subsection{The chemical biology of proteins}

This section covers research advances in topics as diverse as amino acid and peptide chemistry, studies on enzyme mechanisms and the use of proteins in synthesis (biocatalysis).

The structure of small peptides and glucopeptides containing the unnatural $(1 S, 2 S)-1$ amino-2-hydroxycyclobutane carboxylic acid $\left(\mathrm{C}_{4} \mathrm{Ser}\right.$ ) residue has been studied (FernandezTejada et al., 2009). In addition, the synthesis of 2-arylated tyrosine analogues (Bedford et 
al., 2009) and a diverse series of 5-oxopiperazine-2-carboxylates for use as amino acid isosteres have been reported (Limbach et al., 2009). Penmacric acid, an optically active C-4 substituted pyroglutamic acid has been successfully prepared (Berini et al., 2009). Following optimisation of the conditions required for use of the Dmab amino acid protecting group, the solid phase synthesis of $N$-linked glycopeptides was achieved (Conroy et al., 2009). A new 1,2-dimethylindole-3-sulfonyl group for the protection of the arginine side chain has been reported (Isidro et al., 2009). A novel one-pot hydroformylation/Strecker synthesis of a-aminonitriles has been developed (Subhani et al., 2009). A new route to enone-derived aamino acids has been described and used to prepare a novel fluorescent a-amino acid for use as a potential biological probe (Fowler et al., 2009). A range of non-proteinogenic phenylalanine analogues were synthesised successfully via a Rh- catalysed cycloaddition reaction (Garcia et al., 2009). The Ru-catalysed synthesis of $N, N$-diallyl and $N, N, O$-triallyl amino acids has been reported without the need for protecting groups (Sundararaju et al., 2009). A novel series of 10-12 membered ring cyclic amino acids containing an enediyne functionality has been reported (Kaiser et al., 2009) The unnatural 4-amino-3hydroxytetrahydrofuran-2-carboxylic acid has been incorporated into a a,y-cyclic tetrapeptide that has been shown to self-assemble (Reiriz et al., 2009). A method for the preparation of $\mathrm{N}$ - or $\mathrm{C}$-terminus mercaptoimidazoles from amino acids is described (Crepin et al., 2009). The Ugi multi-component reaction was used in the preparation of azabicyclic derivatives for use as peptide mimics (Basso et al., 2009).

Cyclic peptides, based on the $3_{10}$ helical Pro138-Gly144 segment of aquaporin- 4 were prepared by olefin metathesis (O. Jacobsen et al., 2009). The synthesis of tetravalent peptide conjugates has been reported using a cyclic peptide template and unprotected peptide monomers (Avrutina et al., 2009). A cyclic bile-acid peptide conjugate was synthesised as a mimic of the HNE loop of the measles virus (Bode et al., 2009). This conjugate was shown to bind the same monoclonal antibodies as HNE itself and therefore may be of use as a new measles vaccine. The development of a novel approach to macrocyclic peptoids for use as ionophores has been reported (De Cola et al., 2009). Cyclotides, disulfide rich cyclic peptides, have been isolated for the first time from the Melicytus family of plants (Trabi et al., 2009). Using solid phase chemistry, a novel A-chain analogue of human relaxin-3 (INSL7) has been synthesised in which the intramolecular disulfide bond is replaced with a non-reducable carbon-carbon bond (Hossain et al., 2009). A novel class of peptidomimetics, $\Psi\left[\mathrm{CH}\left(\mathrm{CF}_{3}\right) \mathrm{NH}\right] \mathrm{Gly}$ peptides, have been reported, which utilises a stereogenic trifluoroethylamine group as a peptide bond mimic (Molteni et al., 2009). The Lossen rearrangement has been used to prepare a-ureidopeptides (Narendra et al., 2009). The importance of hydrogen bonding for the stability and bioactivity of a-helical anti-HIV inhibitory peptides has been described (Oishi et al., 2009). A procedure for the synthesis of peptides containing $C$-terminal $O$-acyl serine or threonine residues has been established (Yoshiya et al., 2009). A route for the synthesis of non-natural peptide foldamers by the post-assembly reaction of the amino-acid side chains has been developed and used to synthesise a series of novel foldamers (Franz et al., 2009). A method for the solid phase preparation of C-terminal peptide a-ketoacids has been described. This functional group can be reacted further using the a-ketoacid-hydroxylamine ligation reaction to afford peptides (Ju \& Bode, 2009). A novel method for the synthesis of peptide alcohols has been developed (A. R. Katritzky et al., 2009). Peptides can also be used as catalysts in organic reactions. A library of histidine-containing octapeptides were screened, as potential catalysts, in the hydrolysis reaction of a pyrene ester (Schmuck et al., 2009). Solid supports have been designed to bind selectively to the phosphate group of peptides which allows any non-phosphorylated peptides 
to be easily removed by filtration (F. Cass \& Tepe, 2009). Activation of spleen tyrosine kinase (Syk) has been achieved by the binding of its $\mathrm{SH} 2$ domain to a tetrapeptide motif containing a phosphotyrosine residue (Kuil et al., 2009). Dendrimers conjugated to this tetrapeptide were synthesised and shown to have high binding affinities to the SH2 domain of Syk.

The main methods used for the specific labelling of proteins have been reviewed (Sunbul \& Yin, 2009). A detailed and useful discussion of the various types of chemistry and new technologies used to modify proteins chemically was provided. A convenient synthesis of a novel water soluble coumarin-based probe, able to tag biomolecules fluorescently, has been reported (Song et al., 2009). A new system for the specific fluorescent labelling of lysine residues in proteins using a modified microbial trans-glutaminase has also been described (Kamiya et al., 2009). Optimisation of the reaction conditions for the low-yielding $S$ nitrosothiol-ascorbate reaction, a reaction frequently exploited to analyse $S$-nitrosocysteinyl residues in proteins, has improved the method (Kirsch et al., 2009). Novel chemiluminescent probes based on dioxetane have been designed and synthesised (Richard et al., 2009). The probes have been used to detect the activities of various proteases. Poly- $N-(2-$ hydroxypropyl) methacrylate chains were synthesised and conjugated to the surface of lysozyme (Tao et al., 2009). The number of conjugated chains could be controlled by altering either the $\mathrm{pH}$ of the conjugation reaction or the molecular weights of the polymers.

There have been many papers published on deducing specific enzyme mechanisms. The first mechanistic study on a mammalian a-methylacyl-CoA racemase, an enzyme overexpressed in some cancers, has been reported (Darley et al., 2009). The enzymatic reaction mechanism of aristolochene synthase was studied using fluorinated farnesyl analogues by Allemann (Figure 3A) (Miller et al., 2009). Upon incubation of farnesyl analogues $\mathbf{4 b}$ and $\mathbf{4 c}$ with the enzyme, fluorinated germacrene $A$ analogues $6 b$ and $6 c$ were obtained, confirming this as an intermediate in the pathway. Since the presence of the fluoro-substituents prevent the formation of the eudesmane cations $7 \mathbf{b}$ and $7 \mathbf{c}$, a mechanism for the formation of this process could be proposed. Squalene-hopene cyclise (SHC) was used for the cyclisation of a $C_{33}$ polyprenoid (Cheng \& Hoshino, 2009). Since the products from this reaction included mono- through to pentacyclic but no hexacyclic compounds, conclusions were drawn about the conformations required for cyclisation to occur. The substrate specificity of UDP-Dgalactopyranose mutase from Klebsiella pneumonia was probed by Field using substituted analogues of UDP-D-galactose (Figure 3B) (Mann et al., 2009). The enzymatic reaction mechanism of catechol dioxygenase was studied in detail (Brivio et al., 2009) and the Cys69 residue in the photoactive yellow protein has been found to play a key role in its colour regulation (Okamoto et al., 2009). The stereochemistry of the acrylate moiety at the $\mathrm{C} 17$ position of chlorophylls $C_{1}$ and $C_{2}$ was determined and its function elucidated (Mizoguchi et al., 2009). 3,6-Difluorocatechol was used as a probe to study the mechanism for suicideinactivation of the tyrosinase enzyme, resulting in a new route of inactivation being proposed (Ramsden et al., 2009).

Several groups have worked on the immobilisation and encapsulation of enzymes for use in chemical reactions (Nakashima et al., 2009, Sopaci et al., 2009 \& de Hoog et al., 2009). Work has also been carried out on the optimisation of enzymatic reactions. A pH based, colorimetric assay has been designed for the determination of transaminase activity by Truppo and Turner (Truppo et al., 2009). Also reported, are three techniques which can be used to push the reaction towards quantitative conversion (Figure 3C). The stereo- and chemo-selective oxidation of thioanisole to its $S$-sulfoxide has been reported (Ricoux et al., 
2009). This transformation was catalysed by an artificial hemoprotein obtained by inserting Fe(III)-meso-tetra- $p$-carboxyphenylporphyrin into xylanase A.

(A)

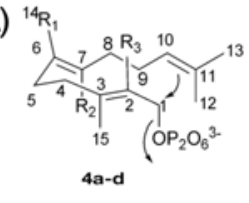

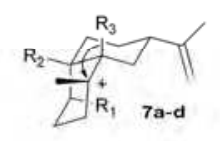<smiles>C1CCCCC1</smiles>
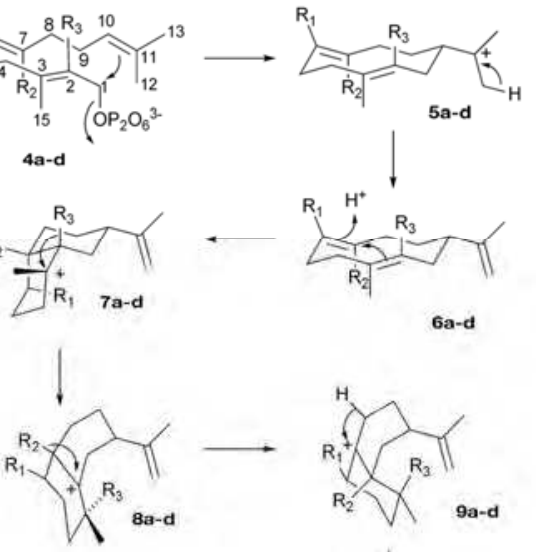

$$
\begin{aligned}
& \text { a } R_{1}, R_{3}=H, R_{2}=C_{3} \\
& \text { b } R_{1}=F, R_{2}=C_{3}, R_{3}=H \\
& \text { c } R_{1}, R_{3}=H, R_{2}=C_{2} F \\
& \text { d } R_{1}=H, R_{2}=C_{3}, R_{3}=F
\end{aligned}
$$
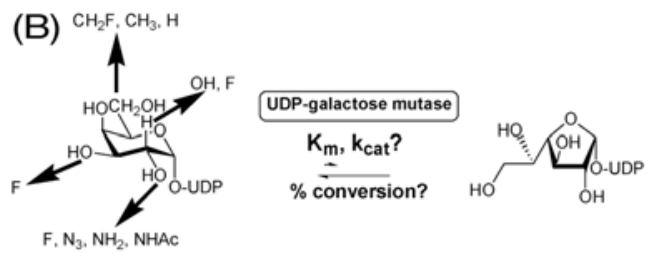

(C)

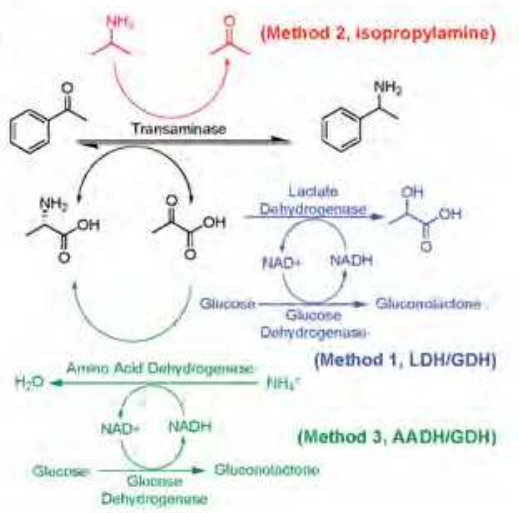

Fig. 3. (A) Aristolochene synthase catalyses the magnesium dependent turnover of FPP (4a) into the sesquiterpene (+)-aristolochene (10a) (Miller et al., 2009).

http://dx.doi.org/10.1039/b817194g (B) Analogues of UDP-D-galactose used to probe the substrate specificity of UDP-D-galactopyranose mutase from Klebsiella pneumonia (Mann et al., 2009). http:/ /dx.doi.org/10.1039/b815549f (C) An overview of the transaminase catalysed reaction sequence (Truppo et al., 2009). http://dx.doi.org/10.1039/b817730a Reproduced by permission of The Royal Society of Chemistry.

Numerous advances in biocatalysis i.e. the use of enzymes to carry out chemical transformations, have been reported. The substrate specificity of the phospho-mannose isomerise/GDP-mannose pyrophosphorylase bifunctional enzyme was probed by the synthesis of a number of nucleotidediphospho-mannoses and guanidinediphospho-hexoses (Mizanur \& Pohl, 2009). The use of FMN-dependant oxidoreductases for the oxidation of $\alpha, \beta$-unsaturated carbonyl compounds and thioethers to the corresponding epoxides and sulfoxides has been reported (Mueller et al., 2009). Biocatalysis has been used to prepare many novel compounds including (-)-striatisporolide A (Deska \& Backvall, 2009), (R)-2-O-aD-glucopyranosyl glycerate (Sawangwan et al., 2009), febrifugine (Wijdeven et al., 2009) and the four different stereoisomers of aszonalenin (W. B. Yin et al., 2009). The solid phase synthesis of peptides using protease catalysis has been described (Haddoub et al., 2009). The chemoenzymatic synthesis of a range of sialyl galactosidases has enabled the substrate selectivity of bacterial sialidases to be explored (Cao et al., 2009). Lipase-catalysed amidation and palladium-catalysed cross coupling of the same substrate were carried out in one pot (Caiazzo et al., 2009). Synthesis and testing of a truncated $N$-glycan hexasaccharide 
oxazoline, a potential substrate for a glycosylation reaction carried out by endohexosaminidases Endo A and Endo M was also reported (Parsons et al., 2009). The synthesis of enantiopure $(R, R)-2,3$-butanediol from glucose was carried out using E.coli and various secondary alcohol dehydrogenases (Yan et al., 2009). An enzyme-mediated synthesis of DNA duplexes containing a large number of locked nucleic acids (LNAs) has been achieved using KOD DNA polymerase (Veedu et al., 2009). A method for the synthesis of polypeptide chains which incorporate an azide-containing sidechain using in vitro translation techniques has been developed (Humenik et al., 2009). A novel method for the preparation of peptide thioesters for further reaction using native chemical ligation has been reported (Kang et al., 2009). (5S)-Hydroxy-2-hexanone was synthesised in $85 \%$ yield with an enantiomeric excess (e.e.) of $>99 \%$ by the mono-reduction of 2,5-hexanedione using S.cerevisiae L13 (Katzberg et al., 2009). A whole cell system, E.coli JM 109(pDTG 601), was used to catalyse the dihydroxylation of the aromatic ring of a number of benzoate esters to the corresponding diols, providing useful intermediates for the synthesis of amino cyclitols and pseudo-sugars (Fabris et al., 2009). New ribozymes which catalyse the Diels-Alder reaction of anthracene and maleimide have been designed (Petermeier \& Jaschke, 2009).

\subsection{Carbohydrates}

The chemical biology of carbohydrates is a very active field with the development of new synthetic routes to these challenging molecules dominating the literature in this area. Ducatti has reported the use of polysaccharides from red seaweed in the synthesis of useful carbohydrate building blocks (Ducatti et al., 2009). Others have described the synthesis of tetrafluorinated ribose and fructose (Linclau et al., 2009), 6-deoxy-6-fluorohexoses (Caravano et al., 2009), difluorinated carbasugar phosphates (Anderl et al., 2009), and pyrrolidine homoazasugars (Blanco et al., 2009). The synthesis of unnatural inositol phosphates, 4-C-methyl-Ins $(1,4,5) \mathrm{P}_{3}$ and 4 -C-methyl-Ins $(1,3,4,5) \mathrm{P}_{4}$ has been reported (Swarbrick et al., 2009). A novel route for the synthesis of the lipid phosphatidyl inositol 4,5biphosphate has been reported (Panchal \& Gaffney, 2009). The selective chloro-Oformylation of sugars using the Vilsmeier reagent (Thota et al., 2009), Rh-catalysed aziridination of glycols (Lorpitthaya et al., 2009), and an appraisal of the utility of the oxoketene cycloaddition methodology in the synthesis of 2,6-dideoxy- and fluorinated 2,6dideoxysugars have also been described (Audouard et al., 2009). A malonate-containing precursor has been shown to facilitate the synthesis of 2-C-branched carbohydrates (J. Yin \& Linker, 2009). The use of the NPPOC photolabile protecting group in the synthesis of glycopyranosides has been explored ( $Y i$ et al., 2009) and the synthesis of pseudooligosacchasrides using cross-metathesis methods (Ronchi et al., 2009) and pseudodisaccharides based on neamine have also been described (Pang et al., 2009). Several studies on the control of glycosylation reactions have also been reported(Belen Cid et al., 2009; Xiaoning Li et al., 2009; Stalford et al., 2009). Studies towards the synthesis of $C$-glycosyl amino acids have been described using $C$-glycosyl 2-iodopropanes and the chiral auxiliary camphorsultam glyoxylic oxime ester (Bragnier et al., 2009). The synthesis of C-glucosyl allothreonine was achieved using this approach. Glucosaminidine ketones have been used as organocatalysts in asymmetric olefin epoxidation reactions (Boutureira et al., 2009).

The structural determination of complex polysaccharides remains a considerable challenge. The relevance of $\mathrm{N}$-hexyl-4-amino glycosides in addressing issues of glycan structure and function has been carefully studied (Suzuki et al., 2009). NMR and molecular modelling 
techniques have been used to study a bacterial exopolysaccharide with an average molecular weight of $1.3 \times 10^{6}$ daltons (Sanchez-Medina et al., 2009). By combining the synthesis and analysis of two oligosaccharides with molecular dynamics simulations, novel insights into the structure of the $S$. enteritidis capsular polysaccharide have been gained (Olsson et al., 2009). N-acetyl-a-D-mannosamine 1-phosphate is a repeating unit in the capsular polysaccharide from Neisseria meningitides serovar A (Toma et al., 2009). The synthesis and NMR analysis of this compound and its analogues provide further insight into the structure of this complex polysaccharide. A ${ }^{13} \mathrm{C}$-labelled $\mathrm{N}$-acetyl derivative of GAG-heparin has been developed to study GAG-protein interactions in amyloid using solid-state NMR methods (Madine et al., 2009).

The in vitro and in cell activity of a series of novel D-glucose derivatives has been reported (van Dijkum et al., 2009). These compounds are proposed to act as chain terminators of cellulose biosynthesis. Two studies on the synthesis and analysis of mannose-functionalised scaffolds have been reported (Andre et al., 2009; Su et al., 2009). In one of these, the nanoparticles ability to bind to concavalin A and sperm surface lectins with high affinity has been reported as a good indicator that these probes will be able to disrupt a range of protein-carbohydrate interactions on the cell surface (Su et al., 2009). A novel approach to the synthesis of oligorotaxanes where the capping group is a carbohydrate has been developed. The conjugates were tested in enzyme linked lectin assays (ELLA) assays for their ability to disrupt carbohydrate-protein interactions (Chwalek et al., 2009).

\subsection{The chemical biology of nucleic acids}

This section covers a wide range of topics in chemical biology. An attempt has been made to group together related studies although, encouragingly, the boundaries are often blurred.

Driven by a desire to study small molecules that bind to and interact with DNA, researchers have prepared a series of macrocyclic polyamines with an appended anthracene unit ( $\mathrm{Yu}$ Huang et al., 2009). They have assessed the ability of these molecules to induce site specific photocleavage of DNA. Esters of pyropheophorbides that contain tetraalkyl ammonium groups have been prepared and their intercalating ability assessed (Taima et al., 2009). The reaction of the naturally occurring DNA damaging agent clerocidin with the four DNA bases has been characterised by Richter et al (Figure 4A) (Richter et al., 2009). Studies on the individual bases and in the context of DNA provided new insights into the mode of action of this compound mode of action. Molecular modelling was also used to provide further insights into clerocidins direct action on DNA and its ability to react with topoisomerase II. Studies on the protonation state as a function of $\mathrm{pH}$ of a dinucleoside monophosphate derivative of the photoadduct that is repaired by the (6-4) photolyase have been carried out (Yamamoto et al., 2009). The selected photoadduct mimics the major UV-induced lesion in DNA. These studies provided an interesting insight into the structure of this compound as well as raising further questions about recognition by and the mechanism of action of the (6-4) photolyase enzyme.

Some of the many challenges inherent in developing RNA intercalators have also been addressed. A hybrid ligand which brings together two weak RNA intercalators has increased binding affinity and enables some specificity to be achieved (Cline \& Waters, 2009). In related work, new artificial oligonucleotides have shown selective recognition of short RNA regions over long RNA targets. These probes are particularly useful for the 
detection of matured miRNAs (Seio et al., 2009). The ability of azacrown-containing Zn(II) complexes to cleave short oligoribonucleotides has been investigated (Laine et al., 2009). Careful analysis of the ability of aminoglycosides to cleave RNA oligonucleotides has progressed the understanding of the mode of action of these drugs (Belousoff et al., 2009). A series of more stable mRNA cap analogues have been synthesised (Rydzik et al., 2009). These compounds were designed to bind tightly to the eukaryotic initiation factor $4 \mathrm{E}$ that is responsible for cap binding during initiation of translation and several of the analogues were indeed potent inhibitors of translation. Novel pyrene-labelled uridine derivatives have been used to study RNA bulges, structures that act as molecular handles in RNA (Jeong et al., 2009).

The synthesis of DNA duplexes containing chemically modified nucleotides continues to yield interesting results. The incorporation of "double-headed" monomers containing two nucleobases into oligonucleotides, however, resulted in no detectable pairing of the additional bases (Umemoto et al., 2009). The effect of incorporating a fluorine atom at the $2^{\prime}$ position of 2'-deoxy nucleotides has been investigated (Figure 4B) (Katolik et al., 2009). The resulting oligonucleotide, known as 2'-FANA was considerably more stable to low and high $\mathrm{pH}$ than DNA or RNA in the absence of enzymes and an interesting dependence on the stability to cleavage by snake venom phosphodiesterase on the stereochemistry at the 2'-F position was observed. Studies on a new type of internucleotide phosphorodithioate linkage have been reported (Olesiak et al., 2009). A set of four 2'-deoxyborononucloleotides have been prepared and structural studies carried out following their incorporation into dinucleotides (A. R. Martin et al., 2009). 2'-Deoxyuridine-5'-triphosphates, functionalised with various linkers on the 5 position of the uridine moiety, were synthesised and their incorporation into DNA strands using two different polymerases were evaluated (Borsenberger et al., 2009). In addition, 8-aza-2'-deoxyguanosine has been shown to be an excellent mimic of dG. As the anion of this reported nucleotide is highly fluorescent, it has been used in the study of DNA mismatches (Seela et al., 2009). A series of novel 8-aza-7deazaguanine nucleotide dye conjugates have been reported with the potential to be used in DNA and RNA sequencing or detection (Seela et al., 2009). An anthroquinone-containing nucleotide has also been incorporated into DNA to facilitate the study of duplexes by electrochemical DNA methods (M. F. Jacobsen et al., 2009). Knowledge of the photochemistry of anthracene has enabled the templated synthesis of a bespoke DNA structure (Mukae et al., 2009). A carefully designed system enabled two DNA-conjugated anthracene units to be in sufficiently close proximity that a light-induced dimerisation reaction could occur. The synthesis of a-L-arabino- and a-D-arabino-containing nucleoside analogues and the effects of their incorporation into oligonucleotides has been reported (Gupta et al., 2009). An analysis of the effect of single-base mismatches on excess electron transfer in DNA has been reported using phenothiazine-modified DNA (Ito et al., 2009). The authors were surprised to find that electron transfer was more efficient in duplexes containing a mismatch, possibly because the mismatch site enables electron injection or hopping beyond this site.

Synthetic methods of relevance to DNA and RNA chemistry continue to be developed (Lakshman \& Frank, 2009, Kaloudis et al., 2009, Edwards et al., 2009, Ducatti et al., 2009 \& Ohkubo et al., 2009).

The chemical biology of DNA quadruplexes continues to develop. The binding of ligands to the human telomeric repeat sequence (h-Tel) and the c-kit promoter has also been explored 
(A)

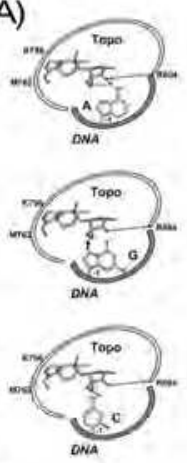

(C)
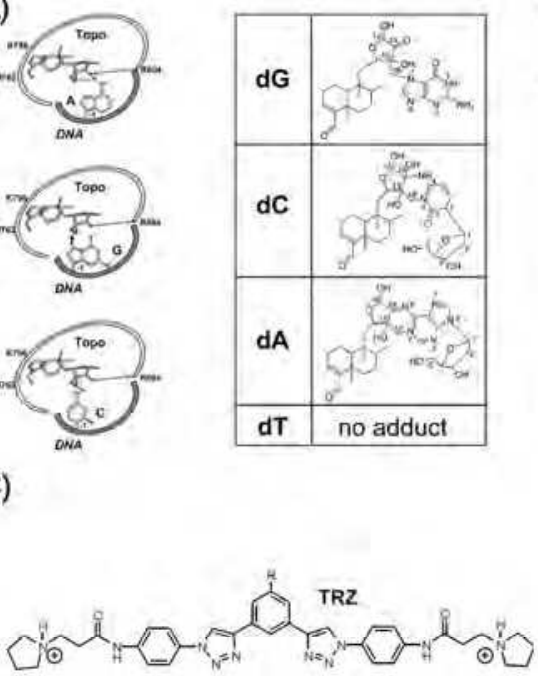

(B)

mesists acidic hydrolysis

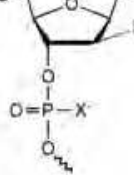

$\longrightarrow$ resists basic hydrolysis

7 one phosphorothioate

diastereomer is selectively cleaved by SVPDE (as for DNA)

(D)
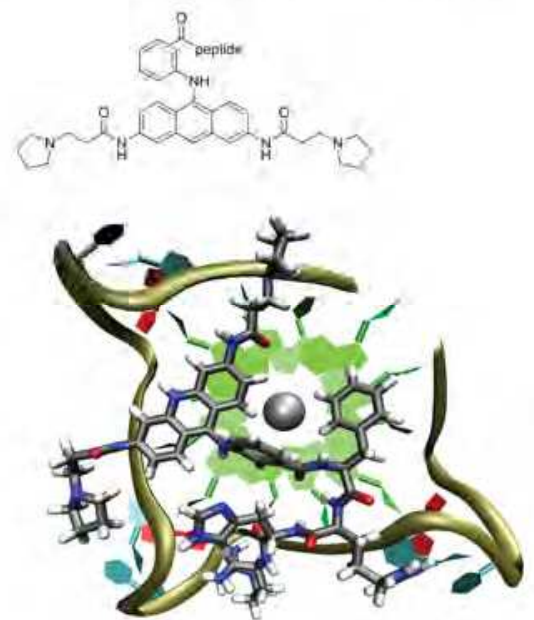

Fig. 4. (A) Schematic representation of clerocidin and $\mathrm{dA}$ or $\mathrm{dG}$ or $\mathrm{dC}$ mutual orientations within the DNA-topoisomerase cleavage complex (enzyme in blue, DNA in red) as suggested by docking experiments and table of the most abundant adducts formed by reaction of clerocidin with DNA deoxyribonucleosides (Richter et al., 2009). http:/ /dx.doi.org/10.1039/b819049f (B) Structure of 2'-FANA and its reported properties (Katolik et al., 2009). http://dx.doi.org/10.1039/b900443b (C) Structures of the small molecule quadruplex binders TRZ and RHPS4 (Garner et al., 2009) http://dx.doi.org/10.1039/b910505k (D) General structure of 9-peptide acridine analogues synthesised and a representative model of a peptide-acridine conjugate docked to the parallel human telomeric quadruplex (Redman et al., 2009) http:/ /dx.doi.org/10.1039/b814682a Reproduced by permission of The Royal Society of Chemistry.

by Moses and Searle using a range of techniques (Figure 4C) (Garner et al., 2009). Two different classes of h-Tel ligands were developed and showed selectivity for parallel or antiparallel conformations respectively. This was rationalised due to the structural plasticity of h-Tel, a property that the c-kit quadruplex does not possess. Research variations in the ability of acridine-peptide conjugates to bind selectively to different DNA quadruplexes as a function of peptide sequence, substitution position on the acridine and the functional group at the C-terminus of the peptide have been investigated by Balasubramanian and Neidle (Figure 4D) (Redman et al., 2009). High degrees of selectivity for the N-ras quadruplex were achieved in some cases. An anti-parallel unimolecular G-quadruplex has been formed by a 
thrombin binding aptamer in the presence of ammonium ions (Trajkovski et al., 2009). Detailed structural information was gained by the use of solution-state NMR techniques when $15 \mathrm{NH}_{4}{ }^{+}$cation was used. The platination of human telomeric G-quadruplex has also been explored with the Pt-complexes showing interesting antiproliferative activity (Bertrand et al., 2009). The strength of binding of the Pt- complex to the quadruplexes increased as the aromatic surface area of the terpyridine-based ligand increased. The most strongly bound complex was shown to interact exclusively with the adenine nucleobases in the loop of the quadruplex. A novel potent and selective G-quadruplex ligand based on a trazatruxene core structure has been developed (Ginnari-Satriani et al., 2009). The ligand's anticancer activity has also been assessed.

The exploration of synthetic analogues of DNA has proved a popular area of study with reports on the development of both GNA (glycol nucleic acid) and PNA (peptide nucleic acid) appearing. Novel phosphoramidites that enable the incorporation of hydroxypyridone and pyridopurine homo- and hetero-base pairs into GNA have been prepared. Interestingly, these reagents were used in conjunction with automated GNA solid phase synthesis techniques to compare the metal binding capacity of the resulting GNA to the analogous DNA duplexes (Schlegel et al., 2009). GNA containing fluorescent nucleotides have also been prepared (Hui Zhou et al., 2009). A novel nucleobase known as PPT has been synthesised and incorporated into PNA (Hirano et al., 2009) and interesting studies on novel metal-containing PNAs have been reported (Sosniak et al., 2009). The introduction of a disulfide bond into the main chain of PNA enabled the facile removal of the PNA from its duplex and invasion complexes with DNA (Aiba \& Komiyama, 2009). This was achieved following reduction of the disulfide linkage in the complexes leading to the formation of short PNA fragments. The ability of poly( $m$-phenylene) to act as an artificial helical polymer has been studied (Ben et al., 2009).

\subsection{The study of bioactive compounds}

Researchers interested in the identification, optimisation and study of bioactive compounds remain an important component of the chemical biology community. This is reflected in the number of papers published in this area. In an attempt to provide some structure to this large section of the review it has been split into sub-sections that cover reports on: (1) compound classes that exhibit antibacterial, antiviral, anticancer and other activities; (2) the synthesis, isolation and biosynthesis of natural products; (3) medicinal chemistry which includes studies on approaches to drug delivery and studies on the metabolism of bioactive compounds and (4) chemical genetics.

\subsubsection{Bioactives}

A large number of bioactive compounds with a range of activities were reported in $\mathrm{OBC}$ in 2009. Compounds with antibacterial activity included sulfone-based nucleotide isosteres which were shown to be inhibitors of CMP-sialic acid synthetase, an important enzyme in bacterial polysaccharide biosynthesis (Wong et al., 2009). By using mimics of the substrates and reaction intermediates of 3-deoxy-D-arabino-heptulosonate 7-phosphate (DAH7P) synthase, inhibition of this important bacterial enzyme was achieved (Walker et al., 2009). A synthesis of a library of 2,5-dihydrochorismate analogues has been described by Payne and Abell (Payne et al., 2009). Interestingly, differential activity against 4 different chorismateutilising enzymes was observed (Scheme 5A). New antimicrobial peptides have also been 
reported (Mitra et al., 2009). These dipeptide-based amphiphiles exhibited inhibitory activity against a number of gram-positive and gram-negative bacteria. A solid phase synthesis of argifin, a cyclic pentapeptide chitinase inhibitor, was achieved by Eggleston and applied to the synthesis of a number of analogues (Figure 5B) (Dixon et al., 2009). This work highlighted the key peptide residues required to bind to the enzyme. Polyamide-based minor groove binders have been reported by Suckling to show antibacterial activity (Figure 5C) (Breen et al., 2009). The synthesis and biological evaluation of castanospermine and austriline analogues as glucosaminidase inhibitors has been achieved (Pluvinage et al., 2009). Porphyrin-linked nitroimidazole antibiotics have been found to be selective growth inhibitors of Porphyromonas gingivalis, a bacterium implicated in periodontal disease (Yap et al., 2009)and a novel triazolyl nucleoside, which acts as a nucleoside triphosphate mimic, was prepared as an ATP-competitive inhibitor of the pantothenate kinase of B. Anthracis (Rowan et al., 2009).

The anti-HIV activity of $2^{\prime}, 3^{\prime}$-didehydro-2', $3^{\prime}$-dideoxyuridine $(\mathrm{d} 4 \mathrm{U})$ and $2^{\prime}, 3^{\prime}$-dideoxyuridine (ddU) phosphoramidate derivatives (Mehellou et al., 2009) as well as a series of phosphonate terminated dendrimers have been evaluated (Perez-Anes et al., 2009). A set of hexahydroisobenzofuran nucleosides have been synthesised and tested as potential inhibitors of HIV-1 (Diaz-Rodriguez et al., 2009). One of these compounds had an $\mathrm{EC}_{50}$ of $12.3 \mu \mathrm{M}$ and the activity was rationalised by comparison to the structure of the known HIV drug didanosine. 1,2,3-Triazole acyclonucleotides containing a difluoromethyl phosphonate group have been synthesised and are currently being investigated as potential nucleoside phosphorylase inhibitors (A. Diab et al., 2009). Amongst several possible applications, glycosidase inhibitors, such as a series of novel polyhydroxylated quinolizidines, (Kumari \& Vankar, 2009) have been linked to antiviral drug development. Through the synthesis of a series of multivalent iminosugars, as inhibitors of glycosidases, it was demonstrated that the binding affinity and selectivity of glycosidase inhibition could be altered by multivalency (Diot et al., 2009). Ring modified castanospermine analogues have been evaluated as selective $\beta$-glucosidase inhibitors (Aguilar-Moncayo et al., 2009).

Potential anti-cancer compounds have been reported including a poly-THF spiroketalcontaining compound which is active against both breast and ovarian cancer cell lines (Piccialli et al., 2009). Both enantiomers of (-)-cylindrocyclophane were synthesised and found to have very similar activities against the human colon cancer HCT-116 cells (Yamakoshi et al., 2009). Iron(III)-salen complexes were used to demonstrate that, somewhat surprisingly, the less DNA cleavage activity these compounds showed in vitro, the more efficient they were at inducing apoptosis in MCF7 cells (Ansari et al., 2009). Further evidence has been gathered to support the proposal that it is the quinone methide, formed by two electron reduction of prekinamycin, that is responsible for its cytostatic activity (Khdour \& Skibo, 2009). A series of substituted thienopyrimidines have been synthesised and shown to be cytotoxic to a number of cancer cell lines (Snegaroff et al., 2009) and substituted $O$-galactosyl aldoximes were prepared as selective galectin-3 inhibitors (Tejler et al., 2009). Pyrrolidine 3,4-diols have been reported as a-L-fucosidase inhibitors (MorenoClavijo et al., 2009). A series of new pentacyclic analogues of BRACO-19, a DNA quadruplex binder, have been synthesised and evaluated for their DNA quadruplex binding affinities (Debray et al., 2009). A library of cyclic pentapeptides were synthesised as potential antagonists of CXCR4, a member of the G-protein coupled receptor family, which is implicated in many diseases including cancer (Tanaka et al., 2009). Redox catalysts 
containing selenium and tellurium have been designed and synthesised since compounds with the ability to alter the redox state in cells have potential anti-cancer activity (Mecklenburg et al., 2009). A number of the compounds prepared possess interesting biological activities.

In other areas, polyfunctionalised quinolizidine alkaloids were synthesised and some analogues were discovered to be potent and selective inhibitors of a-glucosidase with potential anti-diabetes applications (Pandey et al., 2009). Methodology was developed to prepare compounds containing a phenothiazine skeleton (Prasad \& Sekar, 2009). This chemistry was illustrated by the synthesis of some anti-histamine agents. A study was carried out to identify selective inhibitors of the human dopamine transporter which did not inhibit the closely related human serotonin and norepinephrine transporters (Riss et al., 2009). Analogues of Salvinorin A have been synthesised and their affinities for the different opioid receptors determined (Simpson et al., 2009). A series of novel proteo-dendrimers, which inhibit apoptosis, have been reported and may be of use in the treatment of apoptosis mediated diseases (Azuma et al., 2009). A detailed study was carried out on Belactosin A, a cyclopropane containing tripeptidic proteasome inhibitor (Yoshida et al., 2009).

(A)<smiles>C=C(OC(=O)O)Oc1ccccc1C(=O)O</smiles>
$\mathrm{OH}$

AS: $K_{1}=200 \mu \mathrm{M}$ IS: $K_{1}=0.36 \mu \mathrm{M}$ ADCS: $K_{1}=120 \mu \mathrm{M}$ ADCS: $K_{1}=635 \mu \mathrm{M}$

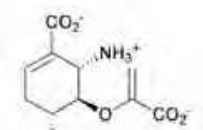

$\mathrm{OH}$

AS: $K_{1}=0.62 \mu \mathrm{M}$ IS: $K_{1}=0.05 \mu \mathrm{M}$

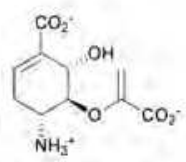

AS: $K_{\mathrm{i}}=6.3 \mu \mathrm{M}$ Is $K_{1}=0.45 \mu \mathrm{M}$ ADCS: $K_{1}=38 \mu \mathrm{M}$
(C)

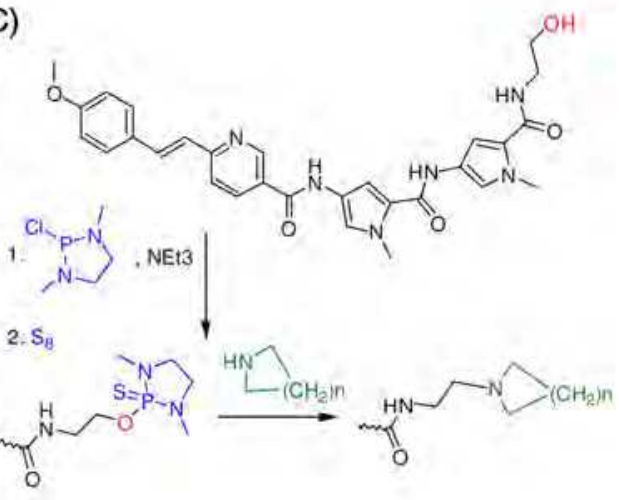

(B)
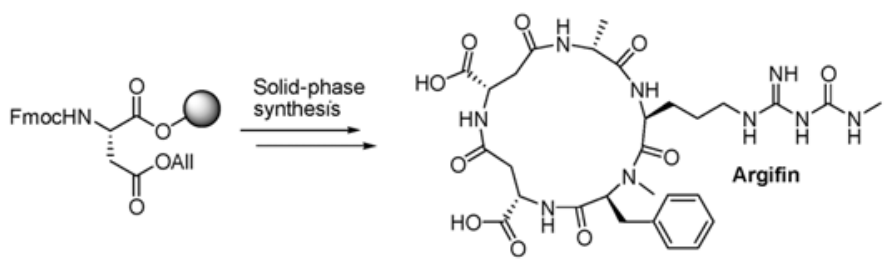

Fig. 5. (A) Inhibition constants for chorismate-utilising enzyme inhibitors (AS = S. marcescens anthranilate synthase, IS $=E$. coli isochorismate synthase and ADCS $=E$. coli ADC synthase) (Payne et al., 2009). http://dx.doi.org/10.1039/b901694e (B) General illustration of the solid phase synthesis of analogues of argifin. This approach enabled an assessment of the role of the various amino acids on the activity of the cyclic peptide as a chitinase inhibitor (Dixon et al., 2009). http://dx.doi.org/10.1039/b815077j (C) Synthesis of polyamide minor groove binders (Breen et al., 2009). http://dx.doi.org/10.1039/b814452d Reproduced by permission of The Royal Society of Chemistry. 
A number of papers have been published on the synthesis of privileged chemical structures which are likely to be of relevance to the discovery of new biologically active molecules. A method for the regioselective synthesis of 1-phenyl pyrazoles, a fragment present in many bioactive compounds, has been reported (Ko et al., 2009). Since isoindolines have been shown to exhibit biological activities including the inhibition of COX-2, a new synthetic strategy for the synthesis of 1-aryl substituted isoindolines has been developed (Clary et al., 2009). An approach for the diversity-oriented synthesis of non-symmetrical malonate analogues has been reported since 2-alkyl and 2-arylmalonates have been shown to posses a wide range of biological activities including the inhibition of HIV-1 and -2 proteases (Ramachary et al., 2009). The synthesis of 3,5-diarylpyrazolines from readily available starting materials has been reported (Mahe et al., 2009). The ring closing metathesis of allylseleno compounds has been reported for the synthesis of bicyclic $\beta$-lactams containing selenium (Garud et al., 2009). Incorporation of the $\mathrm{CF}_{3}$ group in a bioactive compound can have a dramatic effect on its properties. For this reason the synthesis of $\mathrm{CF}_{3}$-substituted heterocyclic boronic acids and esters has been reported and their utility in the synthesis of novel pharmacophores has been demonstrated (Clapham et al., 2009). Using an intramolecular [3+2] azide-alkyne cycloaddition, a number of new heterocyclic core structures were obtained which may possess novel biological activities (R. Li et al., 2009). A novel one-pot cascade reaction of $2 \mathrm{H}-1$,4-benzoxazin-3-(4H)-ones, a scaffold present in the enediyne antitumour antibiotics, has been reported (D. Chen et al., 2009). A series of C-8 arylated adenines have been synthesised using a new direct arylation methodology, which may be used for the synthesis of potential Hsp90 inhibitors (Sahnoun et al., 2009).

\subsubsection{Natural products - isolation, synthesis and biosynthesis}

The isolation, structural determination and chemical synthesis of natural products continue to be widely studied areas. The first total syntheses of many bioactive natural products was achieved in 2009 (Commeiras et al., 2009, Alvarez-Manzaneda et al., 2009, AlvarezManzaneda et al., 2009, Davis et al., 2009 \& Ribes et al., 2009) The synthesis of novel azaanalogues of staurosporine, K-252a and rebeccamycin have also been reported (McCortTranchepain, 2009). Total syntheses and new approaches to the total synthesis of many other natural products have also been reported (Yi Li et al., 2009, Zhang et al., 2009, Garcia-Egido et al., 2009, Foster et al., 2009, Jiang \& Hamada, 2009, Tang et al., 2009, Oh et al., 2009, Shing \& Cheng, 2009, Poldy et al., 2009, Luo Yang et al., 2009, Ceccon et al., 2009, Coldham et al., 2009 \& Ayats et al., 2009).

The isolation of several new natural products has also been achieved. Two new saponins from Parthenium hysterophorus were found to be potent TNF-a inhibitors (Shah et al., 2009). The successful isolation and structure determination of new cyclodepsipeptides has been reported (Zampella et al., 2009). These compounds, named homophymine B-E and A1-E1, were shown to exhibit potent anti-proliferative effects against several human cancer cell lines. Novel dihydro- $\beta$-agarofuran sesquiterpenes were isolated and several were shown to be anticancer multi-drug resistant reversal agents (Torres-Romero et al., 2009). Glycosylated analogues of versipelostatin, a GRP78/Bip molecular chaperone down regulator, were isolated (Zhao et al., 2009). It was concluded that the $\alpha$-L-oleandropyranosyl $(1 \rightarrow 4)-\beta-D-$ digitoxopyranosyl residue of the sugar moiety may be the key feature required for this activity. Five new members of the actinomycin family of antibiotics, $Y_{1}-Y_{5}$, have been isolated (Bitzer et al., 2009). Their structures differ from the Z-type actinomycins and this 
was shown to affect their biological activities. By examining the structure of (-)-ternatin, an important fat-accumulation inhibitor, by NMR and CD spectroscopy, it was concluded that the $\beta$-turn structure is key to the observed inhibitory effect in 3T3-L1 murine adipocytes (Shimokawa et al., 2009). The full relative stereochemistry of 13,19-didesmethyl spirolide C has been assigned by analysis of NMR data and using computational methods (Ciminiello et al., 2009). The preferred conformation of this natural product was also studied and will provide useful information for studies on the mechanism of action of the spirolide class of natural products. The potent bioactivity and unusual structures of the Garcinia xanthones led to a study to assign the pharmacophore of this class of natural products (Figure 6A) (Chantarasriwong et al., 2009). Synthesis of various analogues and subsequent biological evaluation led to the conclusion that the $\mathrm{ABC}$ ring system with the caged structure of ring $\mathrm{C}$ is essential for the observed activity. Studies conducted with cluvenone, a member of this family, demonstrated that these compounds exhibit cytotoxicity in leukemia cells which are multi-drug resistant.

(A)
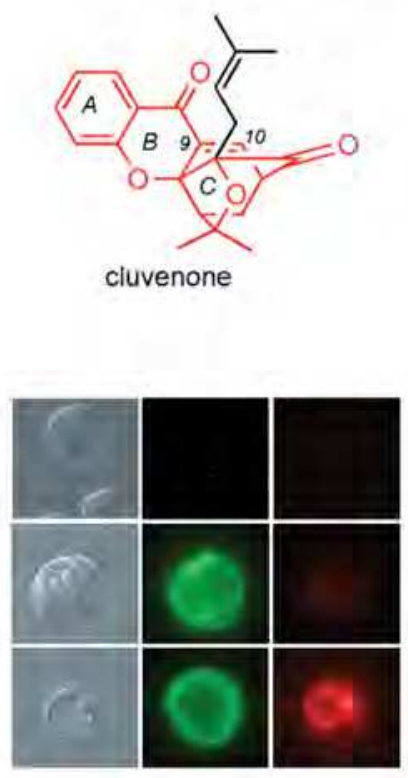

(B)

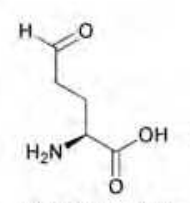

L-glutamate semialdehyde (L-GSA) 1
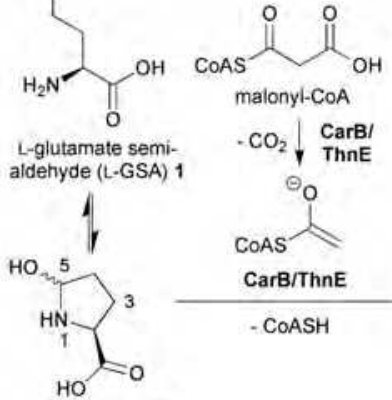

malonyl-CoA

$-\mathrm{CO}_{2}$, ThnE
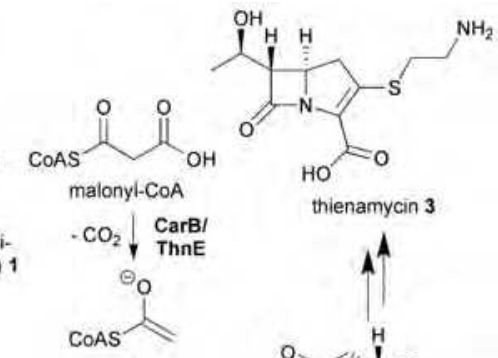

L-5-hydroxyproline

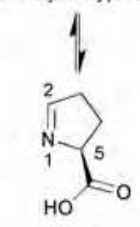

L-pyrroline5-carboxylate (P5C)

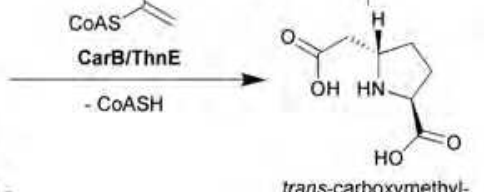

trans-carboxymethylproline ( $t$-CMP) 4

CarA
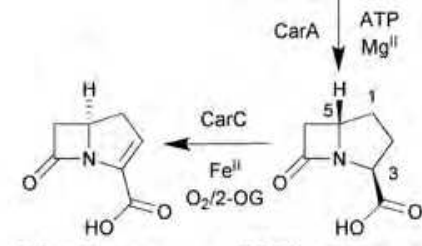

(5R)-carbapenem3-carboxylate 2
$(3 S, 5 S)$-carbapenam3-carboxylate 5

Fig. 6. (A) Structure of cluvenone and the demonstration of induction of apoptosis in HL60/ADR cells by cluvenone visualised by differential interference contrast microscopy (left column) and fluorescence microscopy (middle and right columns). Control untreated cells are shown in the top row. Treated cells undergoing early and late stage apoptosis are shown in the middle and bottom rows respectively (Chantarasriwong et al., 2009) http://dx.doi.org/10.1039/b913496d (B) Outline of the proposed biosynthesis of the carbapenems. Detailed studies provided novel insights into the chemical transformation catalysed by CarB/ThnE (Ducho et al., 2009). http:/ /dx.doi.org/10.1039/b903312b Reproduced by permission of The Royal Society of Chemistry. 
Extending our understanding of the biosynthesis of natural products and hijacking these pathways to deliver novel compounds remain important sub-sections of chemical biology. Using labelling experiments it was demonstrated that pyrrolylpolyenes, fungal natural products from Auxarthron umbrinum are synthesised from proline, methionine, acetate and pyrrole-2-carboxylate (Clark \& Murphy, 2009). The synthesis of key intermediates in several biosynthetic pathways has also been reported and the intermediates used to understand further these pathways. For example, studies on the biosynthesis of Fosfomycin, were carried out by supplementing the growth media with chemically synthesised hypothesised intermediates (McGrath et al., 2009). The synthesis of UDP-Glc-2,3-diNAcA, a key intermediate in the biosynthesis of cell surface polysaccharides, was accomplished and the compound used to study this process (Rejzek et al., 2009). Using synthesised glycosylated seco-iridoid steroisomers, the first steps in monoterpine indole alkaloid biosynthesis were studies (Bernhardt et al., 2009). The stereoselective synthesis of deuterated analogues of Lglutamate was accomplished by Schofield and the analogues used in a study on carbapenem biosynthesis (Figure 6B) (Ducho et al., 2009). A report on the first a-ketoglutarate-dependant dioxygenase with non-heme $\mathrm{Fe}(\mathrm{II})$ to catalyse the formation of an endoperoxide bond has appeared (Steffan et al., 2009). This enzyme was shown to convert fumitremorgin B to verruculogen by the insertion of an endoperoxide bond using both oxygen atoms of $\mathrm{O}_{2}$. Examples of the synthesis of novel natural products by manipulating biosynthetic pathways include the preparation of a new fluorinated analogue of iturin A (Moran et al., 2009). By incubating Bacillus subtilis with 3-fluoro-L-tyrosine, this unnatural amino acid is incorporated in the product, replacing D-tyrosine. Since the activity of iturin A is dependent on this tyrosine residue the incorporation of this modified tyrosine may result in a change in its biological activity. Through the overexpression of biosynthetic genes encoding the first steps of the deoxyhexose biosynthetic pathway, TDP-L-olivose was obtained. This carbohydrate was then used as a substrate of spinosyn glycosyl transferase resulting in the synthesis of a novel sugar appended spinosyn analogue (Gaisser et al., 2009). A new chemical biology based approach, known as chemical epigenetics, involves the use of small molecule inhibitors of HDACs and DNA methyltransferases to activate selectively gene clusters that encode biosynthetic enzymes. A novel natural product, nygerone A was produced from the fungus Aspergillus niger using this approach (Henrikson et al., 2009).

\subsubsection{Medicinal chemistry}

Medicinal chemistry is an important and widely studied area of chemical biology. This area encompasses many research topics including drug metabolism, drug/gene delivery as well as detailed SAR studies on biologically active molecules with potential as drugs. The transacylation kinetics of acyl glucoronides (AGs) has been studied in detail (Berry et al., 2009). Since many non-steroidal anti-inflammatory drugs are metabolised as their AGs, this study highlights issues relating to the metabolism and pharmacokinetics of these wellknown drugs. The thermal degradation of kynurenines was studied as these compounds may be important in cataract formation (Kopylova et al., 2009) and the synthesis of [1,3,5${ }^{13} C_{3}$ ] gallic acid was completed for use as an internal standard for studies on the bioavailability and metabolism of tea catechins (Marshall et al., 2009).

A new pro-drug approach for the delivery of cytarabine, a potent anti-tumour agent, has been reported by Tanabe and Nishimoto (Figure 7A) (Hirata et al., 2009). This involved conjugating cytarabine with a 2-oxopropyl group which upon treatment with X-rays releases cytarabine by a one-electron reduction process. It was shown that by using this approach, the drug was 
released preferentially in hypoxic tumour cells leading to increased cytotoxicity. The intestinal peptide, PepT1, is capable of transporting thiodipeptide prodrugs and may be an interesting target for drug delivery applications (Foley et al., 2009; Foley et al., 2009). Amino acidquinoline antibiotic conjugates are used as prodrugs for the delivery of the quinoline antibiotics. A new route for the synthesis of these conjugates has been reported (A. R. Katritzky et al., 2009). A "bio-oxidisable" pro-drug strategy has been reported for the delivery of new acetylcholinesterase inhibitors (Bohn et al., 2009) and a series of polyamine conjugated naphthalimides have been prepared to exploit the polyamine transporter for drug delivery (Tian et al., 2009). A novel method for the delivery of cytotoxic peptides into cells has been reported (Foillard et al., 2009). The method relies on the use of an RGA-containing scaffold which is anchored to the required peptide. It has also been demonstrated that a fluorescent peptide could be transported using this method allowing monitoring of its activity in cells. Modifying the structure of compounds to enable them to cross the blood-brain barrier remains a challenging area within medicinal chemistry. Recent work illustrated the ability of the 1,4dihydroquinoline derivatives to cross the blood-brain barrier (Foucout et al., 2009). Rats were injected with radio-labelled 1,4-dihydroquinoline $\left[{ }^{11} \mathrm{C}\right]$ and the level of radioactivity in their brains was studied. It was concluded that the $\left[{ }^{11} \mathrm{C}\right]$ carrier was able to penetrate into the central nervous system (CNS). This concept was exemplified by conjugation of the carrier to GABA, a well-known neurotransmitter which is poor at crossing the blood-brain barrier. After injection in mice their locomotor activity was altered significantly, consistent with the expected effect of GABA once it has entered the CNS.

(A)
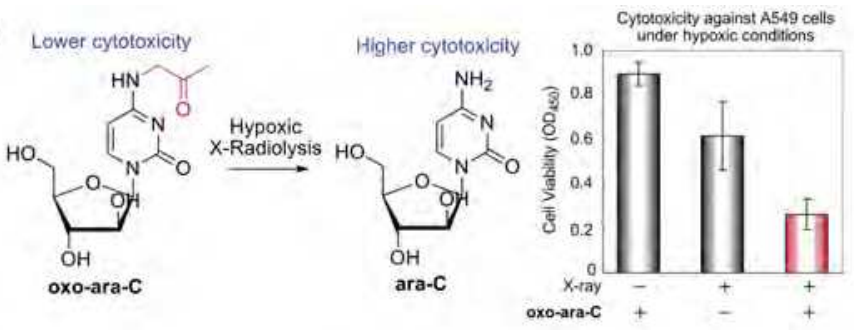

(B)

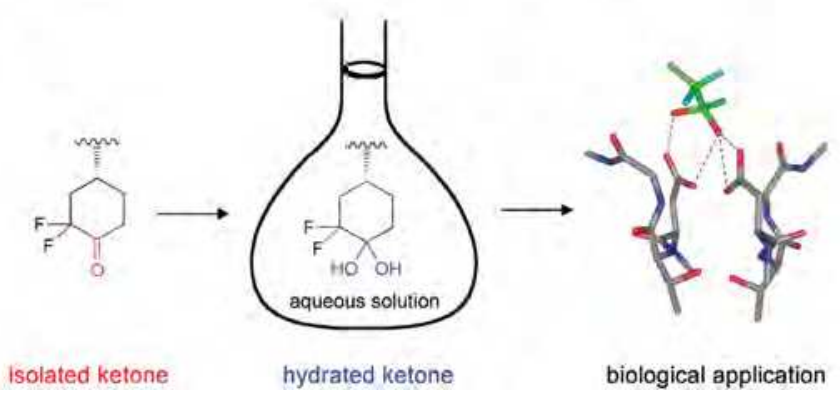

Fig. 7. (A) Cytarabine conjugated with a 2-oxopropyl group which upon treatment with Xrays releases cytarabine. The resulting cytotoxicity against A549 cells is also shown (Hirata et al., 2009) http://dx.doi.org/10.1039/b816194a (B) The structure of alicyclic a,adifluoroketone hydrates and one of the known binding modes for this structural class of inhibitors in aspartic proteases (Fah et al., 2009). http:/ / dx.doi.org/10.1039/b908489d Reproduced by permission of The Royal Society of Chemistry. 
Kinases remain an important target in medicinal chemistry and several reports focus on the discovery and/or optimisation of kinase inhibitors. A novel irreversible inhibitor of EGFR tyrosine kinase has been identified (Ban et al., 2009). A series of bisubstrate inhibitors of the Abelson tyrosine kinase, a kinase implicated in CML, has been identified with some of the inhibitors being as potent as the drug Imatinib against this target (Kalesh et al., 2009).

Several examples of research on parasite-derived diseases have been published. SAR studies on the use of a melamine core structure have been reported (Baliani et al., 2009). This structural component exploits the plasma membrane transporters in trypanosomes to transport potent compounds anchored to the core selectively into the parasite. Many compounds demonstrated very promising activity in vitro. Diversity-oriented synthesis was used in the synthesis of fused pyrimidine analogues (Gibson et al., 2009). The compounds were tested against pteridine reductases from protozoan parasites and several were found to be active. SAR studies revealed the key structural components required for inhibition. A study by Diederich on the inhibition of plasmepsins, an important target for the treatment of drug resistant forms of malaria, has identified novel alicyclic a,a-difluoroketone hydrates as micromolar inhibitors of isoforms II and IV (Figure 7B) (Fah et al., 2009). Novel SF $5^{-}$ containing analogues of mefloquine, an anti-malarial, were synthesised and shown to possess both increased selectivity and potency against various malaria-causing parasites (Wipf et al., 2009). A series of inhibitors of protein farnesyltransferase, an important target in both anti-cancer and anti-parasitic fields were also synthesised (Kerherve et al., 2009). Click chemistry was used efficiently in the synthesis of 3-(1,2,3-triazol-1-yl)- and 3(-1,2,3triazol-4-yl)-substituted pyrazolo[3,4-d] pyrimidin-4-amines (Klein et al., 2009). Two of these compounds were shown to exhibit activity against Plasmodium falciparum PfPK7 kinase. These compounds may prove to be interesting lead compounds for the treatment of the most virulent form of malaria.

Known drugs continue to provide a source of inspiration. For example, pyridine and pyrimidine analogues of acetaminophen have been prepared as novel cyclooxygenase inhibitors (Nam et al., 2009). The anthracycline antibiotics are clinically used cancer chemotherapeutics but drug resistance has become an issue and they are known to be cardiotoxic. With this in mind, a new series of glycosylated anthracycline mimics have been synthesised to overcome these problems (Shi et al., 2009). Synthesis of a range of Nefopam analogues was accomplished in a three-step process (Ramachary et al., 2009). Phosphaoseltamivir conjugates were synthesised and used to study influenza neuraminidases (Carbain et al., 2009). Since the 1,4-benzodiazepine moiety is present in well-known drugs such as Valium and Xanax, a study on the synthesis of novel 1,4-benzodiazepin-3-ones was carried out (Pettersson \& Bergman, 2009). Novel Milnacipran derivatives were synthesised as potential anti-depressants (Vervisch et al., 2009).

New photosensitizer agents for use in photodynamic therapy (PDT), have also been reported including a novel series of hydrophilic conjugated porphyrin dimers (Balaz et al., 2009). This series has shown very promising results, including good uptake by cells, strong absorption in the necessary range, good photostability and excellent efficiency of generation of singlet oxygen (Kuimova et al., 2009). Importantly, the conjugates are more effective at killing human ovarian adenocarcinoma cells, under both one- and two-photon activation, than the clinically used photosensitisor Visudyne® (Dahlstedt et al., 2009). New glucosylated zinc (II) phthalocyanines have been reported as potential photosensitisor agents (J-Y. Liu et al., 2009). The anti-microbial activity of a 2-aminoimidazole-triazole 
conjugate, a known biofilm dispersal agent, in combination with a photodynamic inactivation (PDI) agent has been demonstrated (Rogers et al., 2009). This combination of PDI and a biofilm dispersal agent was shown to have a synergistic effect and could be used to control colonisation of drug resistant bacteria.

The design of transfection aids to enable gene therapy is currently a well-studied topic. Elongation of long chain saturated fatty acids (greater than C18) led to increased transfection of cationic lipids, leading to novel compounds with promising transfection abilities (Liberska et al., 2009). Click chemistry was used for the synthesis of $\beta$-cyclodextrans as potential systems for gene delivery (Mendez-Ardoy et al., 2009) and the synthesis of poly6-cationic amphiphilic cyclodextrins has been reported for the same purpose (Byrne et al., 2009). Biotinylated disulfide containing polyethyleneimine was conjugated to avidin to give a novel gene vector which was shown to have high transfection efficacy in HepG2 cells (Zeng et al., 2009). Research has also been ongoing on the use of dendrimers for gene delivery. New carbosilane dendrimers which are capable of acting as dual carriers for therapeutic and imaging agents have been described (Ortega et al., 2009). Small dendritic structures, that are unable to transfect on their own, have been shown to increase the levels of transfection when used in combination with Lipofectamine $2000^{\mathrm{TM}}$, a cationic vector (Hardy et al., 2009).

An analogue of the trisaccharide repeating unit of Streptococcus pneumonia capsular polysaccharide was prepared and shown to exhibit similar biological activities to the natural carbohydrate but with increased stability to hydrolysis making it a promising compound for vaccine development (Legnani et al., 2009).

\subsubsection{Chemical genetics}

The development and use of chemical tools to study biological processes is often referred to as chemical genetics. Papers covering several aspects of the chemical genetic approach appeared in OBC in 2009. Here we focus initially on the synthesis of novel compound collections for use in chemical genetics. The high-throughput synthesis of an azide library for use in "click" reactions was reported (Srinivasan et al., 2009). A small library of novel spiroacetal-containing nucleosides was synthesised which may possess novel bioactivities (Choi \& Brimble, 2009). 24- and 48-well silicon carbide plates were evaluated for their use in library synthesis by microwave irridation (Stencel et al., 2009). Libraries of biaryls, 1,4dihydropyridines and $N$-aryl functionalised $\beta$-amino esters were successfully prepared in 48-well plates using this approach. A route to 3,5-isoxazole sulfonamides and sulfonate esters has been developed which will allow access to a diverse library of substituted isoxazole analogues in the future (Lee et al., 2009). A review describing various methods of generating dynamic combinatorial libraries was published which also discussed the utility of these libraries (Herrmann, 2009).

Work carried out in our own lab, in collaboration with researchers at the University of Vermont, is focused on the discovery of novel tools to advance understanding of the important process of host cell invasion by the parasite Toxoplasma gondii. We reported the identification of a novel inhibitor of this process, Conoidin A (Haraldsen et al., 2009). Attempts to identify the protein target(s) of Conoidin A led us to evaluate the T.gondii protein peroxiredoxin II (TgPrxII) as a possible target. Whilst the use of a TgPrxII knock-out parasites suggested that this was not the relevant target, studies with the purified protein confirmed that Conoidin A was a novel inhibitor of this enzyme. Further studies on the 
mode of inhibition of TgPrxII by Conoidin A and some novel analogues have also been reported by us recently (G. Liu et al., 2010). Our collaborative team has also focused on the use of the yeast-3-hybrid system for the identification of potential protein targets of small molecules (Walton et al., 2009). In the first report in this series we have described the synthesis and preliminary characterisation of a chemical inducer of dimerisation (CID) based on a T.gondii invasion inhibitor. In another approach to protein target identification an affinity matrix derived from the dimeric membrane phospholipid, cardiolipin, was synthesised (Johns et al., 2009). The resulting matrix was used to identify possible protein targets. The synthesis and biological assessment of a set of four stereoisomers of coranatine, a natural phytotoxin, has advanced understanding of the interesting process of stomatal opening in plant guard cells (Okada et al., 2009). In another study involving plant biology, a new family of stringolactone analogues were synthesised and found to promote germination in Orobanche seeds (Bhattacharya et al., 2009). 4a-Bromo-5a-cholestan-3 $\beta$-ol and nor-5a-cholestan-3 $\beta$-ol derivatives were synthesised and used to study the in vivo metabolism of cholesterol through feeding experiments (R. Martin et al., 2009). A series of (25R)-cholesten-26-oic acids were synthesised and evaluated as ligands for the hormonal receptor DAF-12.(R. Martin et al., 2009). The synthesis and biological characterisation of novel SAM mimetics has also been reported by Nelson (Joce et al., 2009). The ability of these ligands to promote the binding of the E.coli methionine repressor (MetJ) to its operator DNA was explored leading to a deeper understanding of this process (Scheme 8A). The synthesis of mannosyl glycolipids containing perfluoroalkyl membrane anchors has also been reported by Webb and Flitsch (Noble et al., 2009). When studies were carried out in vesicles, the lipids either dispersed or formed artificial rafts in the absence or presence of choleseterol respectively (Scheme 8B). More detailed studies using these new tools led the authors to question current thinking about the preorganisation of glycolipids in lipid rafts.

\section{Emerging areas}

We finish this review with two sections that, we believe, reflect the ability of chemical biology to impact in new areas that fall outside the traditional areas discussed in the preceding section. It is this continuing desire for researchers in the chemical biology community to ask new and interesting questions that makes the field so vibrant and exciting. The final paper in the chemical genetics section highlights one very interesting and relatively new area - the chemical biology of natural and artificial membranes. The final section describes innovations that have been reported as research in chemical biology merges into biotechnology.

\subsection{The chemical biology of membranes}

The synthesis of various artificial membranes and ion channels has been described. A novel family of phosphate-linked cyclic oligosaccharides for use as synthetic ionophores has been reported (Licen et al., 2009). Solid phase chemistry was used to prepare novel linear tetraand penta-ester ion channels (Fyles \& Luong, 2009). In a follow-up paper the authors describe the ion transport activity of the synthesised channels (Fyles \& Luong, 2009). A report on the synthesis of a new ion channel containing redox active ferrocine has also appeared (Tsikolia et al., 2009). This channel was shown to be capable of transporting both $\mathrm{Na}^{+}$and $\mathrm{K}^{+}$ions. Amphiphilic zinc porphyrins have been incorporated into liposomal bilayer membranes (Murakami et al., 2009). 

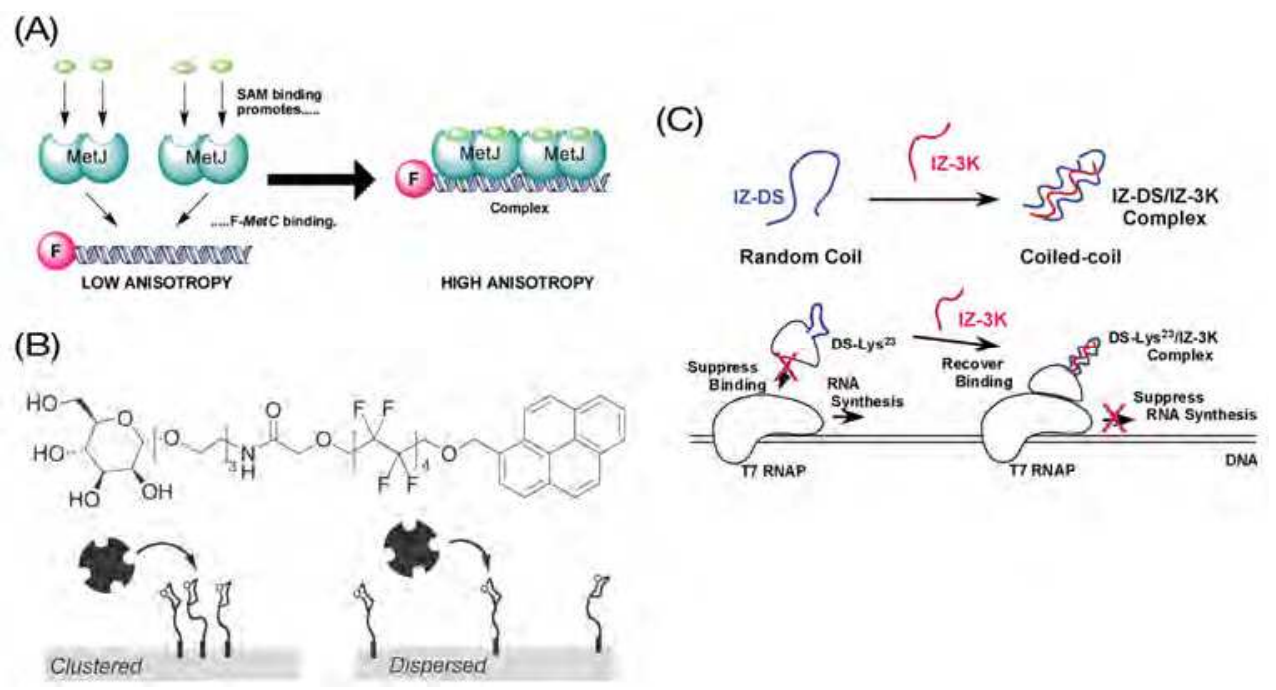

Fig. 8. (A) Cartoon illustrating the fluorescence anisotropy assay. Binding of SAM molecules promotes formation of a SAM-F-metC-protein complex, with two MetJ dimers bound to the 18 base-pair DNA duplex (Joce et al., 2009) http:/ / dx.doi.org/10.1039/b816495a (B) Binding of multivalent lectins to mannosylated lipids that are in artificial "lipid rafts" or dispersed over the bilayer surface could change the lateral distribution of these lipids but increasing the distance between the surface and the mannosyl group may facilitate chelation of the multivalent lectin (Noble et al., 2009) http:/ / dx.doi.org/10.1039/b910976e (C) Schematic illustration of the ligand-induced switch that turns off DNA synthesis (Mizuno et al., 2009). http://dx.doi.org/10.1039/b901118h Reproduced by permission of The Royal Society of Chemistry.

\subsection{From chemical biology to biotechnology}

The synthetic accessibility of DNA continues to inspire novel applications in biotechnology. For example, a 2D-DNA nanoarray has been constructed in which different metal complexes are positioned at regular intervals (Ghosh et al., 2009). Nucleobases and nucleoside end capped structures have been incorporated into novel compounds of relevance to the synthesis of molecular tectons for new types of porous solids (Schindler et al., 2009). Novel tectons have also been accessed using click chemistry (Plietzsch et al., 2009). In this case selfcomplementary DNA chains were incorporated in the tectons. The combination of novel acridinium esters with methyl red has provided a new high sensitivity ligand binding assay format that has been applied to the study of nucleic acid hybridisation (R. C. Brown et al., 2009). A novel detection system has been used to identify a single nucleotide difference on the leukemia-related bcr/abl gene (Furukawa et al., 2009). The system takes advantage of a new fluorogenic naphthorhodamine ligand that is reduced when it finds itself in close proximity to a DNA strand ending in triphenylphosphine. This reduction-trigger leads to the reduced ligand fluorescing at $650 \mathrm{~nm}$. A DNase 1 resistant molecular beacon has been synthesised using a benzene-phosphate backbone at its stem (Ueno et al., 2009).

Changes in $\mathrm{pH}$ have been used as a trigger to control a gold nanoparticle-peptide interaction (Wagner et al., 2009). Only when the peptide adopts a helical conformation was the nanoparticle able to bind. The synthesis of novel bionanomaterials has been advanced 
through the use of repeating units of an amyloidogenic peptide derived from the Alzheimer $\mathrm{A} \beta$ sequence (van Dijk et al., 2009). The heteromeric self-assembly of gp27-gp5, proteins from the bacteriophage T4, has been used to generate novel bionanomaterials in which the position of fluorescent probes is controlled (Koshiyama et al., 2009). The incorporation of a negatively charged polyelectrolyte within the capsid of the cowpea chlorotic mottle virus has been reported (Minten et al., 2009). The resulting monodisperse $18 \mathrm{~nm}$ particles had novel redox properties. The switching of a random coil module, engineered into a protein (T7 ) lysozyme, to a coiled-coil on addition of a peptide ligand has been used to investigate the effect of the induced structural change on binding of T7 lysozyme to T7 RNAP (Figure 8C) (Mizuno et al., 2009). This system was characterised by studying the effect of the peptide on RNA synthesis. Genetic engineering of the heme binding pocket in human serum albumin has led to the identification of a crucial triad of amino acids at the entrance to the pocket (Komatsu et al., 2009). With the goal of understanding better the role that adhesion and aggregation of cells plays in tissue organisation and growth, detailed studies using large unilamellar vesicles as models for cells have been carried out (Feng \& Otto, 2009). An interesting report on novel methods of fingerprint protection has been published (Plater et al., 2009) and decaging methodology has been applied to TRPV1 agonists and antagonists (Van Ryssen et al., 2009).

\section{Conclusion}

The purpose of this chapter has been to explore at the grass roots level the types of research that currently fall under the chemical biology umbrella and to assess which of these are of potential relevance to the drug discovery process. It is clear that chemical biology is a broad church but it remains important that a clear definition is developed of what research in this field involves. An excellent way to help the greater scientific community comprehend the benefits that chemical biology provides and the challenges it faces, is to consult the established experts in the field. A recent review (Altmann et al., 2009) and a series of excellent books (Schreiber \& Kapoor, 2007; Begley, 2009; Bunnage, 2010) have achieved this. Here we take a complementary approach by reviewing the papers that were published in chemical biology in OBC in 2009. We have structured our review to emphasise: i) that chemical biology is built on a core set of research techniques and reagents and that the continued development of these skills and tools is essential; ii) that there remain 4 main areas that the term chemical biology encompasses but the boundaries between these areas are increasingly blurred as the field advances and iii) that new areas are emerging within chemical biology.

Figure 9 shows a breakdown of the 339 papers we reviewed as a function of the category we placed the research in. We believe that several important trends arise from this analysis:

1. The category termed bioactives appears of most direct relevance to drug discovery. It describes research towards novel anti-bacterials, -virals, -parisitics and anticancer agents. It also includes examples of the development of pro-drugs, metabolism studies, advances in photodynamic therapy and transfection reagents for gene therapy.

2. Developments in the synthesis of privileged chemical structures and studies on natural products remain common and, with chemical genetics, have a clear link to drug discovery.

3. The discovery of novel reagents and techniques in analytic aspects of chemical biology, including imaging, are a major focus of the community and this area is developing rapidly. These studies are rapidly enhancing our ability to probe the environment inside cells and this will impact on cell biology studies aimed at defining the function of bioactives. 
4. There is considerable interest in the synthesis and analysis of chemical structures that fall outside conventional chemical space including purity assessment of biologics, synthesis and analysis of cyclic peptides and peptoids, carbohydrates and the study of modified DNA, GNA and PNA.

5. The chemical biology community continues to push forward our understanding of how biological systems function through fundamental studies on proteins (eg. enzyme function), carbohydrates and DNA/RNA (eg. DNA quadruplexes). Advances in the analysis of post-translational modifications and the labelling of proteins will also be of importance in this area.

6. What is certain is that the chemical biology community will not stand still and the recent interest in both membrane (chemical) biology as well as the increasing focus on biotechnological applications (particularly of DNA-based or DNA-inspired systems) reflects this. Information on understudied areas of biology and on new technologies may turn out to be of great relevance to drug discovery.

Whilst we, as academic researchers, are probably not the best people to judge which flavour of chemical biology will have the greatest impact on drug discovery, we hope this chapter helps people as they think about its future and the role that chemical biology has to play in it.

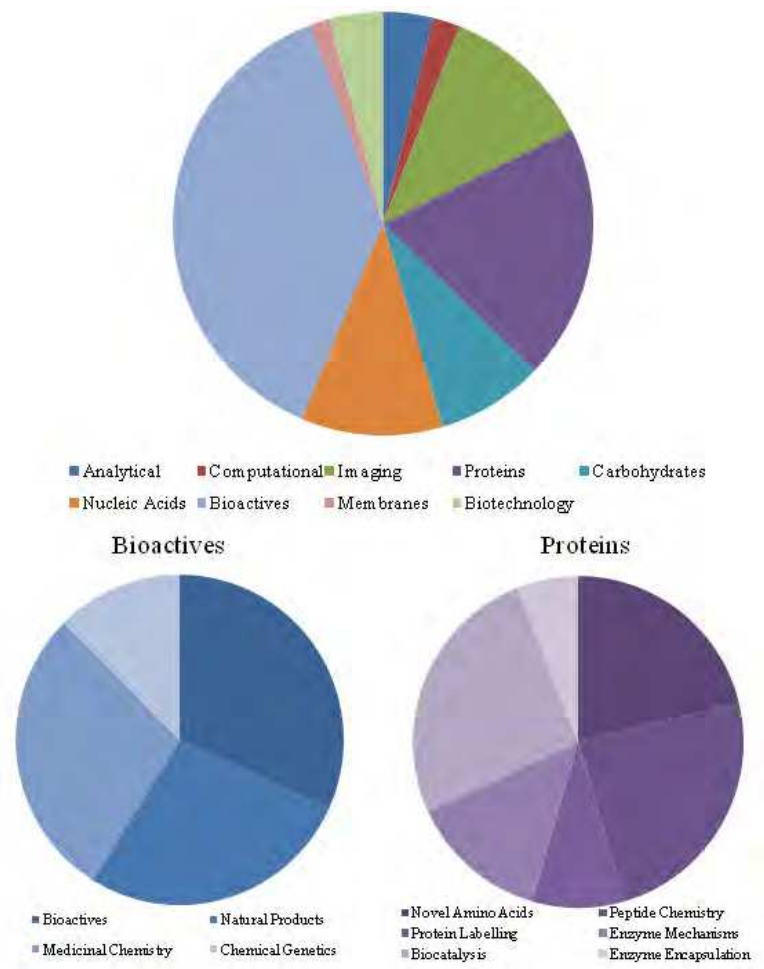

Fig. 9. Numbers of chemical biology papers published in the RSC journal Organic and Biomolecular Chemistry in 2009 as a function of category paper was assigned to. A key detailing the various categories is provided above. A breakdown of the two major categories of protein research and bioactives is also given. 


\section{Acknowledgments}

We would like to thank the Royal Society (NJW fellowship), SULSA (LP PhD funding) and CRUK (LP PhD funding) for financial support. We would also like to thank the Royal Society of Chemistry for their permission to use figures taken directly from their journal.

\section{References}

Aguilar-Moncayo, M., Gloster, T. M., et al. (2009). Organic \& Biomolecular Chemistry Vol. 7, No. 13, 2738-2747.

Aiba, Y.\&Komiyama, M. (2009). Organic \& Biomolecular Chemistry Vol. 7, No. 24, 5078-5083.

Altevogt, D., Hrenn, A., et al. (2009). Organic \& Biomolecular Chemistry Vol. 7, No. 19, 39343939.

Altmann, K.-H., Buchner, J., et al. (2009). ChemBioChem Vol. 10, No. 1, 16-29.

Alvarez-Manzaneda, E., Chahboun, R., et al. (2009). Organic \& Biomolecular Chemistry Vol. 7, No. 24, 5146-5155.

Amel Diab, S., Hienzch, A., et al. (2009). Organic \& Biomolecular Chemistry Vol. 7, No. 21, 4481-4490.

Anderl, T., Audouard, C., et al. (2009). Organic \& Biomolecular Chemistry Vol. 7, No. 24, 52005206.

Andersson, A. S., Diederich, F., et al. (2009). Organic \& Biomolecular Chemistry Vol. 7, No. 17, 3474-3480.

Andre, S., Velasco-Torrijos, T., et al. (2009). Organic E Biomolecular Chemistry Vol. 7, No. 22, 4715-4725.

Ansari, K. I., Grant, J. D., et al. (2009). Organic \& Biomolecular Chemistry Vol. 7, No. 5, 926-932.

Audouard, C., Bettaney, K., et al. (2009). Organic \& Biomolecular Chemistry Vol. 7, No. 8, 15731582.

Avrutina, O., Empting, M., et al. (2009). Organic \& Biomolecular Chemistry Vol. 7, No. 20, 4177-4185.

Ayats, C., Soley, R., et al. (2009). Organic \& Biomolecular Chemistry Vol. 7, No. 5, 860-862.

Azuma, H., Yoshida, Y., et al. (2009). Organic \& Biomolecular Chemistry Vol. 7, No. 8, 17001704.

Balaz, M., Collins, H. A., et al. (2009). Organic \& Biomolecular Chemistry Vol. 7, No. 5, 874-888.

Baliani, A., Peal, V., et al. (2009). Organic \& Biomolecular Chemistry Vol. 7, No. 6, 1154-1166.

Ban, H. S., Usui, T., et al. (2009). Organic \& Biomolecular Chemistry Vol. 7, No. 21, 4415-4427.

Barge, A., Cappelletti, E., et al. (2009). Organic E Biomolecular Chemistry Vol. 7, No. 18, 38103816.

Basso, A., Banfi, L., et al. (2009). Organic \& Biomolecular Chemistry Vol. 7, No. 2, 253-258.

Bedford, R. B., Haddow, M. F., et al. (2009). Organic \& Biomolecular Chemistry Vol. 7, No. 15, 3119-3127.

Begley, T. P. (2009). Wiley Encyclopedia of Chemical Biology, Wiley.

Belen Cid, M., Alfonso, F., et al. (2009). Organic \& Biomolecular Chemistry Vol. 7, No. 7, 14711481.

Belousoff, M. J., Graham, B., et al. (2009). Organic \& Biomolecular Chemistry Vol. 7, No. 1, 3033.

Ben, T., Furusho, Y., et al. (2009). Organic \& Biomolecular Chemistry Vol. 7, No. 12, 2509-2512.

Berini, C., Pelloux-Leon, N., et al. (2009). Organic \& Biomolecular Chemistry Vol. 7, No. 21, 4512-4516. 
Bernhardt, P., Yerkes, N., et al. (2009). Organic \& Biomolecular Chemistry Vol. 7, No. 20, 41664168.

Berry, N. G., Iddon, L., et al. (2009). Organic \& Biomolecular Chemistry Vol. 7, No. 12, 25252533.

Bertrand, H., Bombard, S., et al. (2009). Organic \& Biomolecular Chemistry Vol. 7, No. 14, 28642871.

Bhattacharya, C., Bonfante, P., et al. (2009). Organic E Biomolecular Chemistry Vol. 7, No. 17, 3413-3420.

Bitzer, J., Streibel, M., et al. (2009). Organic E Biomolecular Chemistry Vol. 7, No. 3, 444-450.

Blanco, O., Pato, C., et al. (2009). Organic \& Biomolecular Chemistry Vol. 7, No. 11, 2310-2321.

Blaser, G., Sanderson, J. M., et al. (2009). Organic \& Biomolecular Chemistry Vol. 7, No. 24, 5119-5128.

Bode, C. A., Bechet, T., et al. (2009). Organic \& Biomolecular Chemistry Vol. 7, No. 17, 33913399.

Bohn, P., Le Fur, N., et al. (2009). Organic E Biomolecular Chemistry Vol. 7, No. 12, 2612-2618.

Bonnet, C. S., Massue, J., et al. (2009). Organic \& Biomolecular Chemistry Vol. 7, No. 15, 30743078.

Borsenberger, V., Kukwikila, M., et al. (2009). Organic \& Biomolecular Chemistry Vol. 7, No. $18,3826-3835$.

Boutureira, O., McGouran, J. F., et al. (2009). Organic \& Biomolecular Chemistry Vol. 7, No. 20, 4285-4288.

Bragnier, N., Guillot, R., et al. (2009). Organic \& Biomolecular Chemistry Vol. 7, No. 19, 39183921.

Breen, D., Kennedy, A. R., et al. (2009). Organic \& Biomolecular Chemistry Vol. 7, No. 1, 178186.

Brivio, M., Schlosrich, J., et al. (2009). Organic \& Biomolecular Chemistry Vol. 7, No. 7, 13681373.

Brown, L. J., Ma, N., et al. (2009). Organic \& Biomolecular Chemistry Vol. 7, No. 3, 564-575.

Brown, R. C., Li, Z., et al. (2009). Organic \& Biomolecular Chemistry Vol. 7, No. 2, 386-394.

Bunnage, M. E. (2010). New Frontiers in Chemical Biology, RSC Publishing.

Butterfield, S. M., Hennig, A., et al. (2009). Organic \& Biomolecular Chemistry Vol. 7, No. 9, 1784-1792.

Byrne, C., Sallas, F., et al. (2009). Organic E Biomolecular Chemistry Vol. 7, No. 18, 3763-3771.

Caiazzo, A., Garcia, P. M. L., et al. (2009). Organic \& Biomolecular Chemistry Vol. 7, No. 14, 2926-2932.

Cao, H., Li, Y., et al. (2009). Organic \& Biomolecular Chemistry Vol. 7, No. 24, 5137-5145.

Caravano, A., Field, R. A., et al. (2009). Organic \& Biomolecular Chemistry Vol. 7, No. 5, 9961008.

Carbain, B., Martin, S. R., et al. (2009). Organic \& Biomolecular Chemistry Vol. 7, No. 12, 25702575.

Ceccon, J., Danoun, G., et al. (2009). Organic \& Biomolecular Chemistry Vol. 7, No. 10, 20292031.

Chantarasriwong, O., Cho, W. C., et al. (2009). Organic \& Biomolecular Chemistry Vol. 7, No. 23, 4886-4894.

Chen, D., Shen, G., et al. (2009). Organic \& Biomolecular Chemistry Vol. 7, No. 19, 4067-4073.

Chen, Y.-W., Rick, J., et al. (2009). Organic \& Biomolecular Chemistry Vol. 7, No. 3, 488-494.

Cheng, J.\&Hoshino, T. (2009). Organic \& Biomolecular Chemistry Vol. 7, No. 8, 1689-1699.

Choi, K. W.\&Brimble, M. A. (2009). Organic \& Biomolecular Chemistry Vol. 7, No. 7, 1424-1436. 
Chwalek, M., Auzely, R., et al. (2009). Organic \& Biomolecular Chemistry Vol. 7, No. 8, 16801688.

Ciminiello, P., Catalanotti, B., et al. (2009). Organic \& Biomolecular Chemistry Vol. 7, No. 18, 3674-3681.

Clapham, K. M., Batsanov, A. S., et al. (2009). Organic \& Biomolecular Chemistry Vol. 7, No. 10, 2155-2161.

Clark, B. R.\&Murphy, C. D. (2009). Organic \& Biomolecular Chemistry Vol. 7, No. 1, 111-116.

Clary, K. N., Parvez, M., et al. (2009). Organic \& Biomolecular Chemistry Vol. 7, No. 6, 12261230.

Cline, L. L.\&Waters, M. L. (2009). Organic \& Biomolecular Chemistry Vol. 7, No. 22, 4622-4630.

Coldham, I., Jana, S., et al. (2009). Organic E Biomolecular Chemistry Vol. 7, No. 8, 1674-1679.

Commeiras, L., Thibonnet, J., et al. (2009). Organic \& Biomolecular Chemistry Vol. 7, No. 3, 425-427.

Conroy, T., Jolliffe, K. A., et al. (2009). Organic \& Biomolecular Chemistry Vol. 7, No. 11, 22552258.

Crepin, A., Wattier, N., et al. (2009). Organic \& Biomolecular Chemistry Vol. 7, No. 1, 128-134.

Dahlstedt, E., Collins, H. A., et al. (2009). Organic \& Biomolecular Chemistry Vol. 7, No. 5, 897904.

Darley, D. J., Butler, D. S., et al. (2009). Organic \& Biomolecular Chemistry Vol. 7, No. 3, 543552.

Davis, F. A., Song, M., et al. (2009). Organic \& Biomolecular Chemistry Vol. 7, No. 24, 50675073.

De Cola, C., Licen, S., et al. (2009). Organic \& Biomolecular Chemistry Vol. 7, No. 14, 2851-2854.

de Hoog, H. M., Nallani, M., et al. (2009). Organic \& Biomolecular Chemistry Vol. 7, No. 22, 4604-4610.

Debray, J., Zeghida, W., et al. (2009). Organic \& Biomolecular Chemistry Vol. 7, No. 24, 52195228.

Deska, J.\&Backvall, J.-E. (2009). Organic \& Biomolecular Chemistry Vol. 7, No. 17, 3379-3381.

Dhenin, S. G. Y., Moreau, V., et al. (2009). Organic \& Biomolecular Chemistry Vol. 7, No. 24, 5184-5199.

Diaz-Rodriguez, A., Sanghvi, Y. S., et al. (2009). Organic \& Biomolecular Chemistry Vol. 7, No. 7, 1415-1423.

Didier, P., Ulrich, G., et al. (2009). Organic \& Biomolecular Chemistry Vol. 7, No. 18, 3639-3642.

Diot, J., Garcia-Moreno, M. I., et al. (2009). Organic \& Biomolecular Chemistry Vol. 7, No. 2, 357-363.

Dixon, M. J., Nathubhai, A., et al. (2009). Organic \& Biomolecular Chemistry Vol. 7, No. 2, 259268.

Drewry, J. A., Fletcher, S., et al. (2009). Organic \& Biomolecular Chemistry Vol. 7, No. 24, 50745077.

Ducatti, D. R. B., Massi, A., et al. (2009). Organic \& Biomolecular Chemistry Vol. 7, No. 9, 19801986.

Ducatti, D. R. B., Massi, A., et al. (2009). Organic \& Biomolecular Chemistry Vol. 7, No. 3, 576588.

Ducho, C., Hamed, R. B., et al. (2009). Organic \& Biomolecular Chemistry Vol. 7, No. 13, 27702779.

Dumartin, M.-L., Givelet, C., et al. (2009). Organic \& Biomolecular Chemistry Vol. 7, No. 13, 2725-2728. 
Edwards, W. F., Young, D. D., et al. (2009). Organic \& Biomolecular Chemistry Vol. 7, No. 12, 2506-2508.

Elsinghorst, P. W., Hartig, W., et al. (2009). Organic \& Biomolecular Chemistry Vol. 7, No. 19, 3940-3946.

Escudier, J.-M., Dupouy, C., et al. (2009). Organic \& Biomolecular Chemistry Vol. 7, No. 16, 3251-3257.

Fabris, F., Collins, J., et al. (2009). Organic \& Biomolecular Chemistry Vol. 7, No. 12, 2619-2627.

Fah, C., Hardegger, L. A., et al. (2009). Organic \& Biomolecular Chemistry Vol. 7, No. 19, 39473957.

Feau, C., Klein, E., et al. (2009). Organic \& Biomolecular Chemistry Vol. 7, No. 24, 5259-5270.

Feng, G.\&Otto, S. (2009). Organic \& Biomolecular Chemistry Vol. 7, No. 20, 4289-4295.

Fernandez-Tejada, A., Corzana, F., et al. (2009). Organic \& Biomolecular Chemistry Vol. 7, No. 14, 2885-2893.

Foillard, S., Dumy, P., et al. (2009). Organic \& Biomolecular Chemistry Vol. 7, No. 20, 41594162 .

Foillard, S., Sancey, L., et al. (2009). Organic \& Biomolecular Chemistry Vol. 7, No. 2, 221-224.

Foley, D., Bailey, P., et al. (2009). Organic \& Biomolecular Chemistry Vol. 7, No. 6, 1064-1067.

Foley, D., Pieri, M., et al. (2009). Organic \& Biomolecular Chemistry Vol. 7, No. 18, 3652-3656.

Foster, R. S., Huang, J., et al. (2009). Organic \& Biomolecular Chemistry Vol. 7, No. 19, 40524056.

Foucout, L., Gourand, F., et al. (2009). Organic E Biomolecular Chemistry Vol. 7, No. 18, 36663673.

Fowler, L. S., Ellis, D., et al. (2009). Organic E Biomolecular Chemistry Vol. 7, No. 20, 43094316.

Franz, N., Menin, L., et al. (2009). Organic \& Biomolecular Chemistry Vol. 7, No. 24, 5207-5218.

Frawley Cass, S. M.\&Tepe, J. J. (2009). Organic \& Biomolecular Chemistry Vol. 7, No. 16, 32913299.

Furukawa, K., Abe, H., et al. (2009). Organic \& Biomolecular Chemistry Vol. 7, No. 4, 671-677.

Fyles, T. M.\&Luong, H. (2009). Organic \& Biomolecular Chemistry Vol. 7, No. 4, 725-732.

Fyles, T. M.\&Luong, H. (2009). Organic \& Biomolecular Chemistry Vol. 7, No. 4, 733-738.

Gabutti, S., Schaffner, S., et al. (2009). Organic \& Biomolecular Chemistry Vol. 7, No. 16, 32223229.

Gaisser, S., Carletti, I., et al. (2009). Organic \& Biomolecular Chemistry Vol. 7, No. 8, 1705-1708.

Garcia-Egido, E., Paz, J., et al. (2009). Organic \& Biomolecular Chemistry Vol. 7, No. 19, 39913999.

Garcia, L., Pla-Quintana, A., et al. (2009). Organic \& Biomolecular Chemistry Vol. 7, No. 23, 5020-5027.

Garner, T. P., Williams, H. E. L., et al. (2009). Organic \& Biomolecular Chemistry Vol. 7, No. 20, 4194-4200.

Garud, D. R., Garud, D. D., et al. (2009). Organic \& Biomolecular Chemistry Vol. 7, No. 12, 2591-2598.

Ghosh, S., Pignot-Paintrand, I., et al. (2009). Organic \& Biomolecular Chemistry Vol. 7, No. 13, 2729-2737.

Gibson, C. L., Huggan, J. K., et al. (2009). Organic \& Biomolecular Chemistry Vol. 7, No. 9, 1829-1842.

Ginnari-Satriani, L., Casagrande, V., et al. (2009). Organic \& Biomolecular Chemistry Vol. 7, No. 12, 2513-2516. 
Gruber, T., Fischer, C., et al. (2009). Organic \& Biomolecular Chemistry Vol. 7, No. 23, 49044917.

Gupta, P., Maity, J., et al. (2009). Organic \& Biomolecular Chemistry Vol. 7, No. 11, 2389-2401.

Ha-Thi, M.-H., Penhoat, M., et al. (2009). Organic \& Biomolecular Chemistry Vol. 7, No. 8, 1665-1673.

Haddoub, R., Dauner, M., et al. (2009). Organic \& Biomolecular Chemistry Vol. 7, No. 4, 665670.

Haraldsen, J. D., Liu, G., et al. (2009). Organic \& Biomolecular Chemistry Vol. 7, No. 15, 30403048 .

Hardy, J. G., Love, C. S., et al. (2009). Organic \& Biomolecular Chemistry Vol. 7, No. 4, 789-793.

Henrikson, J. C., Hoover, A. R., et al. (2009). Organic \& Biomolecular Chemistry Vol. 7, No. 3, 435-438.

Herrmann, A. (2009). Organic \& Biomolecular Chemistry Vol. 7, No. 16, 3195-3204.

Hirano, T., Kuroda, K., et al. (2009). Organic \& Biomolecular Chemistry Vol. 7, No. 14, 29052911.

Hirata, N., Fujisawa, Y., et al. (2009). Organic \& Biomolecular Chemistry Vol. 7, No. 4, 651-654.

Hong, Y. J.\&Tantillo, D. J. (2009). Organic \& Biomolecular Chemistry Vol. 7, No. 19, 4101-4109.

Hossain, M. A., Rosengren, K. J., et al. (2009). Organic \& Biomolecular Chemistry Vol. 7, No. 8, 1547-1553.

Huang, J., Xu, Y., et al. (2009). Organic \& Biomolecular Chemistry Vol. 7, No. 7, 1299-1303.

Huang, Y., Zhang, Y., et al. (2009). Organic \& Biomolecular Chemistry Vol. 7, No. 11, 22782285.

Humenik, M., Huang, Y., et al. (2009). Organic \& Biomolecular Chemistry Vol. 7, No. 20, 42184224 .

Huynh, L., Leroux, J.-C., et al. (2009). Organic \& Biomolecular Chemistry Vol. 7, No. 17, 34373446.

Isidro, A., Latassa, D., et al. (2009). Organic \& Biomolecular Chemistry Vol. 7, No. 12, 25652569.

Ito, T., Kondo, A., et al. (2009). Organic \& Biomolecular Chemistry Vol. 7, No. 10, 2077-2081.

Jacobsen, M. F., Ferapontova, E. E., et al. (2009). Organic \& Biomolecular Chemistry Vol. 7, No. $5,905-908$.

Jacobsen, O., Klaveness, J., et al. (2009). Organic \& Biomolecular Chemistry Vol. 7, No. 8, 15991611.

Jeong, H. S., Kang, S., et al. (2009). Organic E Biomolecular Chemistry Vol. 7, No. 5, 921-925.

Jiang, H.\&Hamada, Y. (2009). Organic \& Biomolecular Chemistry Vol. 7, No. 20, 4173-4176.

Joce, C., Caryl, J., et al. (2009). Organic \& Biomolecular Chemistry Vol. 7, No. 4, 635-638.

Johns, M. K., Yin, M.-X., et al. (2009). Organic \& Biomolecular Chemistry Vol. 7, No. 18, 36913697.

Ju, L.\&Bode, J. W. (2009). Organic \& Biomolecular Chemistry Vol. 7, No. 11, 2259-2264.

Kaiser, J., van Esseveldt, B. C. J., et al. (2009). Organic \& Biomolecular Chemistry Vol. 7, No. 4, 695-705.

Kalesh, K. A., Liu, K., et al. (2009). Organic \& Biomolecular Chemistry Vol. 7, No. 24, 5129-5136.

Kaloudis, P., Paris, C., et al. (2009). Organic \& Biomolecular Chemistry Vol. 7, No. 23, 49654972.

Kamiya, N., Abe, H., et al. (2009). Organic \& Biomolecular Chemistry Vol. 7, No. 17, 3407-3412.

Kang, J., Reynolds, N. L., et al. (2009). Organic \& Biomolecular Chemistry Vol. 7, No. 23, 49184923. 
Katolik, A., Viladoms, J., et al. (2009). Organic \& Biomolecular Chemistry Vol. 7, No. 9, 19041910.

Katritzky, A. R., Abo-Dya, N. E., et al. (2009). Organic \& Biomolecular Chemistry Vol. 7, No. $21,4444-4447$.

Katritzky, A. R., Munawar, M. A., et al. (2009). Organic \& Biomolecular Chemistry Vol. 7, No. 11, 2359-2362.

Katzberg, M., Wechler, K., et al. (2009). Organic \& Biomolecular Chemistry Vol. 7, No. 2, 304314.

Kele, P., Li, X., et al. (2009). Organic \& Biomolecular Chemistry Vol. 7, No. 17, 3486-3490.

Kerherve, J., Botuha, C., et al. (2009). Organic \& Biomolecular Chemistry Vol. 7, No. 10, 22142222.

Khdour, O.\&Skibo, E. B. (2009). Organic \& Biomolecular Chemistry Vol. 7, No. 10, 2140-2154.

Kirsch, M., Buscher, A.-M., et al. (2009). Organic \& Biomolecular Chemistry Vol. 7, No. 9, 19541962.

Klein, M., Diner, P., et al. (2009). Organic \& Biomolecular Chemistry Vol. 7, No. 17, 3421-3429.

Ko, Y. O., Chun, Y. S., et al. (2009). Organic \& Biomolecular Chemistry Vol. 7, No. 6, 1132-1136.

Komatsu, T., Nakagawa, A., et al. (2009). Organic \& Biomolecular Chemistry Vol. 7, No. 18, 3836-3841.

Kopylova, L. V., Snytnikova, O. A., et al. (2009). Organic \& Biomolecular Chemistry Vol. 7, No. 14, 2958-2966.

Koshiyama, T., Ueno, T., et al. (2009). Organic \& Biomolecular Chemistry Vol. 7, No. 12, 26492654.

Kuil, J., Branderhorst, H. M., et al. (2009). Organic \& Biomolecular Chemistry Vol. 7, No. 19, 4088-4094.

Kuimova, M. K., Collins, H. A., et al. (2009). Organic \& Biomolecular Chemistry Vol. 7, No. 5, 889-896.

Kumari, N.\&Vankar, Y. D. (2009). Organic \& Biomolecular Chemistry Vol. 7, No. 10, 2104-2109.

Laine, M., Ketomaki, K., et al. (2009). Organic \& Biomolecular Chemistry Vol. 7, No. 13, 2780 2787.

Lakshman, M. K.\&Frank, J. (2009). Organic \& Biomolecular Chemistry Vol. 7, No. 14, 29332940.

Lee, C. C., Fitzmaurice, R. J., et al. (2009). Organic \& Biomolecular Chemistry Vol. 7, No. 21, 4349-4351.

Legnani, L., Fallarini, S., et al. (2009). Organic \& Biomolecular Chemistry Vol. 7, No. 21, 44284436.

Li, A.-F., He, H., et al. (2009). Organic \& Biomolecular Chemistry Vol. 7, No. 1, 193-200.

Li, C., Li, J., et al. (2009). Organic \& Biomolecular Chemistry Vol. 7, No. 13, 2699-2703.

Li, R., Jansen, D. J., et al. (2009). Organic \& Biomolecular Chemistry Vol. 7, No. 9, 1921-1930.

Li, X., Huang, L., et al. (2009). Organic \& Biomolecular Chemistry Vol. 7, No. 1, 117-127.

Li, Y., Nawrat, C. C., et al. (2009). Organic \& Biomolecular Chemistry Vol. 7, No. 4, 639-640.

Liberska, A., Unciti-Broceta, A., et al. (2009). Organic \& Biomolecular Chemistry Vol. 7, No. 1, 61-68.

Licen, S., Coppola, C., et al. (2009). Organic \& Biomolecular Chemistry Vol. 7, No. 6, 1060-1063.

Limbach, M., Lygin, A. V., et al. (2009). Organic \& Biomolecular Chemistry Vol. 7, No. 16, 33383342.

Lin, H.-H., Su, S.-Y., et al. (2009). Organic \& Biomolecular Chemistry Vol. 7, No. 10, 2036-2039.

Linclau, B., Boydell, A. J., et al. (2009). Organic \& Biomolecular Chemistry Vol. 7, No. 4, 803814. 
Liu, G., Botting, C., et al. (2010). Chemmedchem Vol. 5, No. 1, 41-45.

Liu, J.-Y., Lo, P.-C., et al. (2009). Organic E Biomolecular Chemistry Vol. 7, No. 8, 1583-1591.

Liu, W., Xu, L., et al. (2009). Organic \& Biomolecular Chemistry Vol. 7, No. 4, 660-664.

Lopalco, M., Koini, E. N., et al. (2009). Organic \& Biomolecular Chemistry Vol. 7, No. 5, 856859.

Lorpitthaya, R., Sophy, K. B., et al. (2009). Organic \& Biomolecular Chemistry Vol. 7, No. 7, 1284-1287.

Lu, H., Xiong, L., et al. (2009). Organic \& Biomolecular Chemistry Vol. 7, No. 12, 2554-2558.

Lusvarghi, S., Kim, J. M., et al. (2009). Organic \& Biomolecular Chemistry Vol. 7, No. 9, 18151820.

Madine, J., Clayton, J. C., et al. (2009). Organic \& Biomolecular Chemistry Vol. 7, No. 11, 24142420.

Mahe, O., Frath, D., et al. (2009). Organic \& Biomolecular Chemistry Vol. 7, No. 18, 3648-3651.

Mann, M. C., Fairhurst, S. A., et al. (2009). Organic \& Biomolecular Chemistry Vol. 7, No. 5, 1009-1016.

Marshall, L. J., Cable, K. M., et al. (2009). Organic \& Biomolecular Chemistry Vol. 7, No. 4, 785788.

Martin, A. R., Mohanan, K., et al. (2009). Organic \& Biomolecular Chemistry Vol. 7, No. 21, 4369-4377.

Martin, R., Saini, R., et al. (2009). Organic E Biomolecular Chemistry Vol. 7, No. 11, 2303-2309.

Martin, R., Schmidt, A. W., et al. (2009). Organic E Biomolecular Chemistry Vol. 7, No. 5, 909920.

Mazik, M.\&Buthe, A. C. (2009). Organic \& Biomolecular Chemistry Vol. 7, No. 10, 2063-2071.

McCort-Tranchepain, I. (2009). Organic \& Biomolecular Chemistry Vol. 7, No. 4, 706-716.

McGrath, J. W., Hammerschmidt, F., et al. (2009). Organic \& Biomolecular Chemistry Vol. 7, No. 9, 1944-1953.

Mecklenburg, S., Shaaban, S., et al. (2009). Organic \& Biomolecular Chemistry Vol. 7, No. 22, 4753-4762.

Mehellou, Y., Balzarini, J., et al. (2009). Organic \& Biomolecular Chemistry Vol. 7, No. 12, 25482553.

Mendez-Ardoy, A., Gomez-Garcia, M., et al. (2009). Organic \& Biomolecular Chemistry Vol. 7, No. 13, 2681-2684.

Miller, D. J., Yu, F., et al. (2009). Organic \& Biomolecular Chemistry Vol. 7, No. 5, 962-975.

Minten, I. J., Ma, Y., et al. (2009). Organic \& Biomolecular Chemistry Vol. 7, No. 22, 4685-4688.

Mitra, R. N., Shome, A., et al. (2009). Organic \& Biomolecular Chemistry Vol. 7, No. 1, 94-102.

Mizanur, R. M.\&Pohl, N. L. B. (2009). Organic \& Biomolecular Chemistry Vol. 7, No. 10, 21352139.

Mizoguchi, T., Nagai, C., et al. (2009). Organic \& Biomolecular Chemistry Vol. 7, No. 10, 21202126.

Mizuno, T., Suzuki, K., et al. (2009). Organic \& Biomolecular Chemistry Vol. 7, No. 15, 31023111.

Molteni, M., Bellucci, M. C., et al. (2009). Organic \& Biomolecular Chemistry Vol. 7, No. 11, 2286-2296.

Moran, S., Rai, D. K., et al. (2009). Organic E Biomolecular Chemistry Vol. 7, No. 4, 644-646.

Moreno-Clavijo, E., Carmona, A. T., et al. (2009). Organic \& Biomolecular Chemistry Vol. 7, No. 6, 1192-1202.

Mueller, N. J., Stueckler, C., et al. (2009). Organic \& Biomolecular Chemistry Vol. 7, No. 6, 11151119. 
Mukae, M., Ihara, T., et al. (2009). Organic \& Biomolecular Chemistry Vol. 7, No. 7, 1349-1354.

Murakami, R., Minami, A., et al. (2009). Organic \& Biomolecular Chemistry Vol. 7, No. 7, 14371444.

Nakashima, K., Kamiya, N., et al. (2009). Organic \& Biomolecular Chemistry Vol. 7, No. 11, 2353-2358.

Nam, T.-g., Nara, S. J., et al. (2009). Organic \& Biomolecular Chemistry Vol. 7, No. 24, 51035112.

Narendra, N., Chennakrishnareddy, G., et al. (2009). Organic \& Biomolecular Chemistry Vol. 7, No. 17, 3520-3526.

New, E. J.\&Parker, D. (2009). Organic \& Biomolecular Chemistry Vol. 7, No. 5, 851-855.

Nguyen, T. H.\&Ansell, R. J. (2009). Organic \& Biomolecular Chemistry Vol. 7, No. 6, 1211-1220.

Noble, G. T., Flitsch, S. L., et al. (2009). Organic \& Biomolecular Chemistry Vol. 7, No. 24, 52455254.

Ogino, M., Taya, Y., et al. (2009). Organic \& Biomolecular Chemistry Vol. 7, No. 15, 3163-3167.

Oh, H.-S., Xuan, R., et al. (2009). Organic \& Biomolecular Chemistry Vol. 7, No. 21, 4458-4463.

Ohkubo, A., Kasuya, R., et al. (2009). Organic \& Biomolecular Chemistry Vol. 7, No. 4, 687-694.

Oishi, S., Kamitani, H., et al. (2009). Organic \& Biomolecular Chemistry Vol. 7, No. 14, 28722877.

Okada, M., Ito, S., et al. (2009). Organic \& Biomolecular Chemistry Vol. 7, No. 15, 3065-3073.

Okamoto, K., Hamada, N., et al. (2009). Organic \& Biomolecular Chemistry Vol. 7, No. 18, 3782-3791.

Olesiak, M., Stec, W. J., et al. (2009). Organic E Biomolecular Chemistry Vol. 7, No. 10, 21622169.

Olsson, J. D. M., Landstrom, J., et al. (2009). Organic \& Biomolecular Chemistry Vol. 7, No. 8, 1612-1618.

Ortega, P., Samaniego, R., et al. (2009). Organic E Biomolecular Chemistry Vol. 7, No. 15, 30793085.

Pal, R., Parker, D., et al. (2009). Organic E Biomolecular Chemistry Vol. 7, No. 8, 1525-1528.

Panchal, N.\&Gaffney, P. R. J. (2009). Organic \& Biomolecular Chemistry Vol. 7, No. 23, 48324841.

Pandey, G., Grahacharya, D., et al. (2009). Organic \& Biomolecular Chemistry Vol. 7, No. 16, 3300-3307.

Pang, L.-J., Wang, D., et al. (2009). Organic \& Biomolecular Chemistry Vol. 7, No. 20, 4252-4266.

Park, K. K., Park, J. W., et al. (2009). Organic \& Biomolecular Chemistry Vol. 7, No. 20, 4225-4232.

Parsons, T. B., Moir, J. W. B., et al. (2009). Organic \& Biomolecular Chemistry Vol. 7, No. 15, 3128-3140.

Payne, R. J., Bulloch, E. M. M., et al. (2009). Organic \& Biomolecular Chemistry Vol. 7, No. 11, 2421-2429.

Perez-Anes, A., Spataro, G., et al. (2009). Organic \& Biomolecular Chemistry Vol. 7, No. 17, 3491-3498.

Perez-Ruiz, R., Diaz, Y., et al. (2009). Organic \& Biomolecular Chemistry Vol. 7, No. 17, 34993504.

Petermeier, M.\&Jaschke, A. (2009). Organic \& Biomolecular Chemistry Vol. 7, No. 2, 288-292.

Pettersson, B.\&Bergman, J. (2009). Organic \& Biomolecular Chemistry Vol. 7, No. 6, 1184-1191.

Piccialli, V., Oliviero, G., et al. (2009). Organic \& Biomolecular Chemistry Vol. 7, No. 15, 30363039.

Plater, M. J., Barnes, P., et al. (2009). Organic \& Biomolecular Chemistry Vol. 7, No. 8, 16331641. 
Plietzsch, O., Schilling, C. I., et al. (2009). Organic \& Biomolecular Chemistry Vol. 7, No. 22, 4734-4743.

Pluvinage, B., Ghinet, M. G., et al. (2009). Organic \& Biomolecular Chemistry Vol. 7, No. 20, 4169-4172.

Poldy, J., Peakall, R., et al. (2009). Organic \& Biomolecular Chemistry Vol. 7, No. 20, 4296-4300.

Prasad, D. J. C.\&Sekar, G. (2009). Organic \& Biomolecular Chemistry Vol. 7, No. 24, 5091-5097.

Ramachary, D. B., Narayana, V. V., et al. (2009). Organic \& Biomolecular Chemistry Vol. 7, No. $17,3372-3378$.

Ramachary, D. B., Venkaiah, C., et al. (2009). Organic \& Biomolecular Chemistry Vol. 7, No. 10, 2053-2062.

Ramsden, C. A., Stratford, M. R. L., et al. (2009). Organic \& Biomolecular Chemistry Vol. 7, No. 17, 3388-3390.

Redman, J. E., Granadino-Roldan, J. M., et al. (2009). Organic \& Biomolecular Chemistry Vol. 7, No. 1, 76-84.

Reiriz, C., Amorin, M., et al. (2009). Organic \& Biomolecular Chemistry Vol. 7, No. 21, 43584361.

Rejzek, M., Kannathasan, V. S., et al. (2009). Organic \& Biomolecular Chemistry Vol. 7, No. 6, 1203-1210.

Ribes, C., Falomir, E., et al. (2009). Organic \& Biomolecular Chemistry Vol. 7, No. 7, 1355-1360.

Richard, J.-A., Jean, L., et al. (2009). Organic \& Biomolecular Chemistry Vol. 7, No. 14, 29412957.

Richter, S. N., Menegazzo, I., et al. (2009). Organic \& Biomolecular Chemistry Vol. 7, No. 5, 976985.

Ricoux, R., Allard, M., et al. (2009). Organic E Biomolecular Chemistry Vol. 7, No. 16, 32083211.

Riss, P. J., Hummerich, R., et al. (2009). Organic \& Biomolecular Chemistry Vol. 7, No. 13, 26882698.

Rochat, S., Grote, Z., et al. (2009). Organic \& Biomolecular Chemistry Vol. 7, No. 6, 1147-1153.

Rogers, S. A., Krayer, M., et al. (2009). Organic \& Biomolecular Chemistry Vol. 7, No. 3, 603606.

Rohacova, J., Marin, M. L., et al. (2009). Organic \& Biomolecular Chemistry Vol. 7, No. 23, 49734980.

Ronchi, P., Vignando, S., et al. (2009). Organic \& Biomolecular Chemistry Vol. 7, No. 12, 26352644.

Rosengren-Holmberg, J. P., Karlsson, J. G., et al. (2009). Organic \& Biomolecular Chemistry Vol. 7, No. 15, 3148-3155.

Rouffet, M., Denhez, C., et al. (2009). Organic \& Biomolecular Chemistry Vol. 7, No. 18, 38173825.

Rowan, A. S., Nicely, N. I., et al. (2009). Organic \& Biomolecular Chemistry Vol. 7, No. 19, 40294036.

Rydzik, A. M., Lukaszewicz, M., et al. (2009). Organic \& Biomolecular Chemistry Vol. 7, No. 22, 4763-4776.

Sahnoun, S., Messaoudi, S., et al. (2009). Organic E Biomolecular Chemistry Vol. 7, No. 20, 4271-4278.

Salorinne, K., Tero, T.-R., et al. (2009). Organic \& Biomolecular Chemistry Vol. 7, No. 20, 42114217.

Sanchez-Medina, I., Frank, M., et al. (2009). Organic \& Biomolecular Chemistry Vol. 7, No. 2, 280-287. 
Sawangwan, T., Goedl, C., et al. (2009). Organic \& Biomolecular Chemistry Vol. 7, No. 20, 42674270.

Schindler, D., Ei, et al. (2009). Organic \& Biomolecular Chemistry Vol. 7, No. 17, 3549-3560.

Schlegel, M. K., Zhang, L., et al. (2009). Organic \& Biomolecular Chemistry Vol. 7, No. 3, 476482.

Schmuck, C., Michels, U., et al. (2009). Organic \& Biomolecular Chemistry Vol. 7, No. 21, 43624368 .

Schreiber, S. L.\&Kapoor, T. M. (2007). Chemical Biology: From Small Molecules to Systems Biology and Drug Design Wiley.

Schulz, A., Hornig, S., et al. (2009). Organic \& Biomolecular Chemistry Vol. 7, No. 9, 1884-1889.

Seela, F., Jiang, D., et al. (2009). Organic \& Biomolecular Chemistry Vol. 7, No. 17, 3463-3473.

Seela, F., Xiong, H., et al. (2009). Organic \& Biomolecular Chemistry Vol. 7, No. 7, 1374-1387.

Seio, K., Takaku, Y., et al. (2009). Organic E Biomolecular Chemistry Vol. 7, No. 11, 2440-2451.

Sengupta, R., Billiar, T. R., et al. (2009). Organic \& Biomolecular Chemistry Vol. 7, No. 2, 232234.

Shah, B. A., Chib, R., et al. (2009). Organic \& Biomolecular Chemistry Vol. 7, No. 16, 3230-3235.

Sharrett, Z., Gamsey, S., et al. (2009). Organic \& Biomolecular Chemistry Vol. 7, No. 7, 14611470.

Shi, W., Coleman, R. S., et al. (2009). Organic \& Biomolecular Chemistry Vol. 7, No. 18, 37093722.

Shimokawa, K., Miwa, R., et al. (2009). Organic \& Biomolecular Chemistry Vol. 7, No. 4, 777-784.

Shing, T. K. M.\&Cheng, H. M. (2009). Organic \& Biomolecular Chemistry Vol. 7, No. 24, 50985102.

Shiraishi, Y., Maehara, H., et al. (2009). Organic \& Biomolecular Chemistry Vol. 7, No. 10, 20722076.

Simpson, D. S., Lovell, K. M., et al. (2009). Organic \& Biomolecular Chemistry Vol. 7, No. 18, 3748-3756.

Smith, A. J. T., Li, Y., et al. (2009). Organic \& Biomolecular Chemistry Vol. 7, No. 13, 2716-2724.

Snegaroff, K., Lassagne, F., et al. (2009). Organic \& Biomolecular Chemistry Vol. 7, No. 22, 4782-4788.

Soliman, M. E. S., Pernia, J. J. R., et al. (2009). Organic \& Biomolecular Chemistry Vol. 7, No. 24, 5236-5244.

Soliman, M. E. S., Ruggiero, G. D., et al. (2009). Organic \& Biomolecular Chemistry Vol. 7, No. 3, 460-468.

Song, H. Y., Ngai, M. H., et al. (2009). Organic \& Biomolecular Chemistry Vol. 7, No. 17, 34003406.

Sopaci, S. B., Simsek, I., et al. (2009). Organic \& Biomolecular Chemistry Vol. 7, No. 8, 16581664.

Sosniak, A. M., Gasser, G., et al. (2009). Organic \& Biomolecular Chemistry Vol. 7, No. 23, 49925000 .

Srinivasan, R., Tan, L. P., et al. (2009). Organic \& Biomolecular Chemistry Vol. 7, No. 9, 18211828.

Stalford, S. A., Kilner, C. A., et al. (2009). Organic \& Biomolecular Chemistry Vol. 7, No. 23, 4842-4852.

Steffan, N., Grundmann, A., et al. (2009). Organic \& Biomolecular Chemistry Vol. 7, No. 19, $4082-4087$.

Stencel, L. M., Kormos, C. M., et al. (2009). Organic \& Biomolecular Chemistry Vol. 7, No. 11, 2452-2457. 
Su, R., Li, L., et al. (2009). Organic \& Biomolecular Chemistry Vol. 7, No. 10, 2040-2045.

Subhani, M. A., Muller, K.-S., et al. (2009). Organic \& Biomolecular Chemistry Vol. 7, No. 19, 4000-4008.

Sunbul, M.\&Yin, J. (2009). Organic \& Biomolecular Chemistry Vol. 7, No. 17, 3361-3371.

Sundararaju, B., Achard, M., et al. (2009). Organic \& Biomolecular Chemistry Vol. 7, No. 19, 3906-3909.

Suzuki, K., Tobe, A., et al. (2009). Organic \& Biomolecular Chemistry Vol. 7, No. 22, 4726-4733.

Swarbrick, J. M., Cooper, S., et al. (2009). Organic \& Biomolecular Chemistry Vol. 7, No. 8, 1709-1715.

Taima, H., Yoshioka, N., et al. (2009). Organic \& Biomolecular Chemistry Vol. 7, No. 6, 1176-1183.

Tanaka, T., Nomura, W., et al. (2009). Organic \& Biomolecular Chemistry Vol. 7, No. 18, 38053809.

Tang, B., Bray, C. D., et al. (2009). Organic \& Biomolecular Chemistry Vol. 7, No. 21, 4448-4457.

Tanima, D., Imamura, Y., et al. (2009). Organic \& Biomolecular Chemistry Vol. 7, No. 22, 46894694.

Tao, L., Liu, J., et al. (2009). Organic \& Biomolecular Chemistry Vol. 7, No. 17, 3481-3485.

Tei, L., Gugliotta, G., et al. (2009). Organic \& Biomolecular Chemistry Vol. 7, No. 21, 4406-4414.

Tejler, J., Salameh, B., et al. (2009). Organic \& Biomolecular Chemistry Vol. 7, No. 19, 3982-3990.

Thota, N., Mukherjee, D., et al. (2009). Organic \& Biomolecular Chemistry Vol. 7, No. 7, 12801283.

Tian, Z.-y., Xie, S.-q., et al. (2009). Organic E Biomolecular Chemistry Vol. 7, No. 22, 4651-4660.

Toganoh, M., Miyachi, H., et al. (2009). Organic \& Biomolecular Chemistry Vol. 7, No. 15, 30273030 .

Toma, L., Legnani, L., et al. (2009). Organic \& Biomolecular Chemistry Vol. 7, No. 18, 37343740 .

Torres-Romero, D., Munoz-Martinez, F., et al. (2009). Organic \& Biomolecular Chemistry Vol. 7, No. 24, 5166-5172.

Trabi, M., Mylne, J. S., et al. (2009). Organic \& Biomolecular Chemistry Vol. 7, No. 11, 23782388.

Trajkovski, M., Sket, P., et al. (2009). Organic \& Biomolecular Chemistry Vol. 7, No. 22, 46774684 .

Truppo, M. D., Rozzell, J. D., et al. (2009). Organic \& Biomolecular Chemistry Vol. 7, No. 2, 395398.

Tsikolia, M., Hall, A. C., et al. (2009). Organic \& Biomolecular Chemistry Vol. 7, No. 18, $3862-$ 3870.

Tsou, L. K., Zhang, M. M., et al. (2009). Organic \& Biomolecular Chemistry Vol. 7, No. 24, 50555058.

Ueno, Y., Kawamura, A., et al. (2009). Organic \& Biomolecular Chemistry Vol. 7, No. 13, 27612769.

Umemoto, T., Wengel, J., et al. (2009). Organic \& Biomolecular Chemistry Vol. 7, No. 9, 1793-1797.

van Dijk, M., Dechesne, A. C., et al. (2009). Organic \& Biomolecular Chemistry Vol. 7, No. 21, 4517-4525.

van Dijkum, E., Danac, R., et al. (2009). Organic \& Biomolecular Chemistry Vol. 7, No. 6, 10971105.

Van Ryssen, M. P., Avlonitis, N., et al. (2009). Organic \& Biomolecular Chemistry Vol. 7, No. 22, 4695-4707.

Veale, E. B., Tocci, G. M., et al. (2009). Organic \& Biomolecular Chemistry Vol. 7, No. 17, 34473454 . 
Veedu, R. N., Vester, B., et al. (2009). Organic \& Biomolecular Chemistry Vol. 7, No. 7, 14041409.

Vervisch, K., D'Hooghe, M., et al. (2009). Organic \& Biomolecular Chemistry Vol. 7, No. 16, 3271-3279.

Wagner, S. C., Roskamp, M., et al. (2009). Organic \& Biomolecular Chemistry Vol. 7, No. 1, 46-51.

Walker, S. R., Cumming, H., et al. (2009). Organic \& Biomolecular Chemistry Vol. 7, No. 15, 3031-3035.

Walton, J. G. A., Patterson, S., et al. (2009). Organic \& Biomolecular Chemistry Vol. 7, No. 15, 3049-3060.

Wang, S.-P., Deng, W.-J., et al. (2009). Organic \& Biomolecular Chemistry Vol. 7, No. 19, 40174020.

Watkins, R. W., Lavis, L. D., et al. (2009). Organic \& Biomolecular Chemistry Vol. 7, No. 19, 3969-3975.

Wijdeven, M. A., van den Berg, R. J. F., et al. (2009). Organic \& Biomolecular Chemistry Vol. 7, No. 14, 2976-2980.

Willans, C. E., Anderson, K. M., et al. (2009). Organic \& Biomolecular Chemistry Vol. 7, No. 13, 2756-2760.

Wipf, P., Mo, T., et al. (2009). Organic \& Biomolecular Chemistry Vol. 7, No. 20, 4163-4165.

Wong, J. H., Sahni, U., et al. (2009). Organic \& Biomolecular Chemistry Vol. 7, No. 1, 27-29.

Yamakoshi, H., Ikarashi, F., et al. (2009). Organic \& Biomolecular Chemistry Vol. 7, No. 18, 3772-3781.

Yamamoto, J., Tanaka, Y., et al. (2009). Organic \& Biomolecular Chemistry Vol. 7, No. 1, 161-166.

Yan, Y., Lee, C.-C., et al. (2009). Organic \& Biomolecular Chemistry Vol. 7, No. 19, 3914-3917.

Yang, L., Wang, D.-X., et al. (2009). Organic \& Biomolecular Chemistry Vol. 7, No. 12, 26282634.

Yang, Y.-K., Ko, S.-K., et al. (2009). Organic \& Biomolecular Chemistry Vol. 7, No. 22, 45904593.

Yap, B. C. M., Simpkins, G. L., et al. (2009). Organic \& Biomolecular Chemistry Vol. 7, No. 14, 2855-2863.

Yi, H., Maisonneuve, S., et al. (2009). Organic \& Biomolecular Chemistry Vol. 7, No. 18, 38473854.

Yin, J.\&Linker, T. (2009). Organic \& Biomolecular Chemistry Vol. 7, No. 23, 4829-4831.

Yin, W.-B., Cheng, J., et al. (2009). Organic \& Biomolecular Chemistry Vol. 7, No. 10, 2202-2207.

Yoshida, K., Yamaguchi, K., et al. (2009). Organic \& Biomolecular Chemistry Vol. 7, No. 9, 1868-1877.

Yoshiya, T., Kawashima, H., et al. (2009). Organic \& Biomolecular Chemistry Vol. 7, No. 14, 2894-2904.

Zampella, A., Sepe, V., et al. (2009). Organic \& Biomolecular Chemistry Vol. 7, No. 19, 4037-4044.

Zaubitzer, F., Riis-Johannessen, T., et al. (2009). Organic \& Biomolecular Chemistry Vol. 7, No. 22, 4598-4603.

Zeng, X., Sun, Y.-X., et al. (2009). Organic \& Biomolecular Chemistry Vol. 7, No. 20, 4201-4210.

Zhang, F., Simpkins, N. S., et al. (2009). Organic \& Biomolecular Chemistry Vol. 7, No. 9, $1963-$ 1979.

Zhao, P., Ueda, J.-y., et al. (2009). Organic \& Biomolecular Chemistry Vol. 7, No. 7, 1454-1460.

Zhou, D., Chu, W., et al. (2009). Organic \& Biomolecular Chemistry Vol. 7, No. 7, 1337-1348.

Zhou, H., Ma, X., et al. (2009). Organic \& Biomolecular Chemistry Vol. 7, No. 11, 2297-2302. 


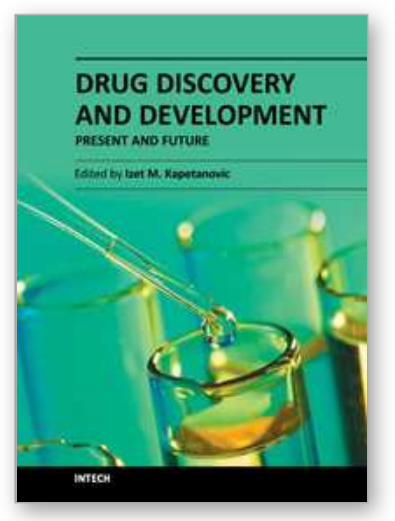

\author{
Drug Discovery and Development - Present and Future \\ Edited by Dr. Izet Kapetanović
}

ISBN 978-953-307-615-7

Hard cover, 528 pages

Publisher InTech

Published online 16, December, 2011

Published in print edition December, 2011

Drug discovery and development process aims to make available medications that are safe and effective in improving the length and quality of life and relieving pain and suffering. However, the process is very complex, time consuming, resource intensive, requiring multi-disciplinary expertise and innovative approaches. There is a growing urgency to identify and develop more effective, efficient, and expedient ways to bring safe and effective products to the market. The drug discovery and development process relies on the utilization of relevant and robust tools, methods, models, and validated biomarkers that are predictive of clinical effects in terms of diagnosis, prevention, therapy, and prognosis. There is a growing emphasis on translational research, a bidirectional bench to the bedside approach, in an effort to improve the process efficiency and the need for further innovations. The authors in the book discuss the current and evolving state of drug discovery and development.

\title{
How to reference
}

In order to correctly reference this scholarly work, feel free to copy and paste the following:

Lisa Pirrie and Nicholas J. Westwood (2011). Chemical Biology: What is Its Role in Drug Discovery?, Drug Discovery and Development - Present and Future, Dr. Izet Kapetanović (Ed.), ISBN: 978-953-307-615-7, InTech, Available from: http://www.intechopen.com/books/drug-discovery-and-development-present-andfuture/chemical-biology-what-is-its-role-in-drug-discovery-

\section{INTECH}

open science | open minds

\author{
InTech Europe \\ University Campus STeP Ri \\ Slavka Krautzeka 83/A \\ 51000 Rijeka, Croatia \\ Phone: +385 (51) 770447 \\ Fax: +385 (51) 686166 \\ www.intechopen.com
}

\author{
InTech China \\ Unit 405, Office Block, Hotel Equatorial Shanghai \\ No.65, Yan An Road (West), Shanghai, 200040, China \\ 中国上海市延安西路65号上海国际贵都大饭店办公楼 405 单元 \\ Phone: +86-21-62489820 \\ Fax: $+86-21-62489821$
}


(C) 2011 The Author(s). Licensee IntechOpen. This is an open access article distributed under the terms of the Creative Commons Attribution 3.0 License, which permits unrestricted use, distribution, and reproduction in any medium, provided the original work is properly cited. 